الآفاق المستقبلية للعلاقات العراقية-الخليجية في المجال العسكري

واثق محمد براك

مدرس مساعد/ قسم الدراسات السياسية والعسكرية/ مركز الدراسات الإقليمية/ جامعة الموصل.

ملخص البحث

فرضية البحث مبنية على رؤية مستقبلية لإقامة تعاون عسكري بين العراق ودول الخليج العربية تضمنت

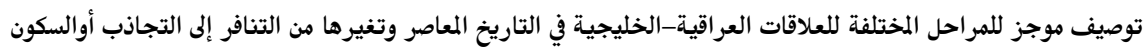
وحسب ظروف المرحلة ومن ثم تم التركيز على هذه العلاقات في مرحلة ما بعد الاحتلال الأمريكي للعراق وتحليل الإشارات والتصريحات التي تصدر من المسؤولين الخليجيين بخصوص العراق(الجديد)،كما حدد البحث النماذج المحتملة والممكنة

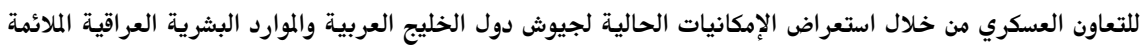

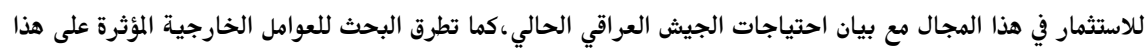
التعاون وركز على العاملين الأمريكي والإيراني بوصفهما الأكثر تأثيراً وتأثراً.

المقدمة

لاشك أننا نمر في فترة مغصلية من التاريخ تنبئ بحدوث تغيرات كبيرة في موازين القوى

العالمية والإقليمية من المؤكد سينتج عنها إعادة تمحور في العلاقات السياسية على المستوى الدولي بشكل عام والمنطقة بشكل خاص، فالعالم يشهد الآن أزمة اقتصادية حادة أثرت على جميع أسواق العالم الأمريكية والأوروبية والآسيوية والعربية وبمستويات مختلفة، ومن الطبيعي أن تكون لهذه الأزمة انعكاساتها على العلاقات بين البلدان، فلازال السؤال الجدلي الذي يصف الرابطة الوثيقة بين السياسة والاقتصاد متداول(هل السياسة تصنع الاقتصاد أم الاقتصاد يصنع السياسة؟)، كما أننا نشهد استقراء لتراجع الهيمنة الأمريكية، قد يبالغ فيه المنظرين المناوئين للسياسة الأمريكية،ويقلل من أهميته المتحمسين لها، لكن مؤشرات التراجع موجودة والاختلاف فقط في تقييمها؛ فالمشروع الأمريكي في المنطقة وحلم (الشرق أوسط الجديد)متعثر، بما يحويه هذا التعثر من تخبط سياسي وعسكري في العراق، يرافقه فشل في تحقيق أي تقدم في الملف الإسرائيلي- الفلسطيني مع عدم وضع حد للطموحات النووية الإيرانية،أووقف تدخلاتها في لبنان والعراق،كما أن قدرة الدبلوماسية 


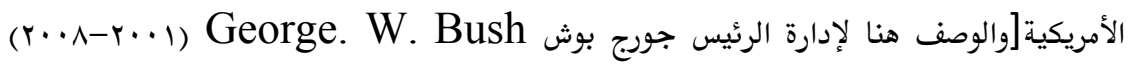
على إيجاد تفاهمات مع دول لا يتناسب حجمها وقدراتها مع استخدام سياسة الترهيب معها مثل

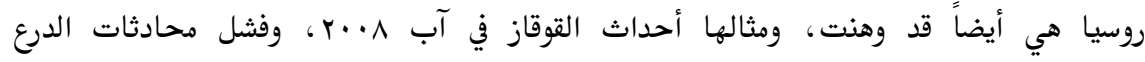

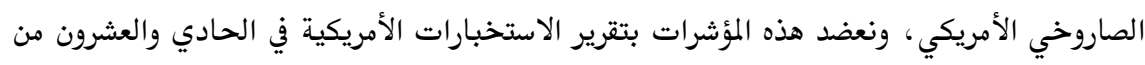

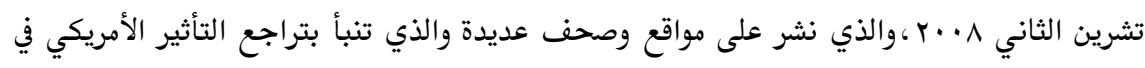
السياسة الدولية في المستقبل القريب وبروز قوة منافسة وركز التقرير على الصين.إن هذه الانعكاسات والاستقراءات تولد لدينا تصور مذطقي بأننا مقبلين على عالم مختلف يتطلب إعادة النظر في علاقاتنا الدولية كما يتطلب بناء إستراتيجيات جديدة لهذه العلاقات بكافة مجالاتها السياسية والاقتصادية والعسكرية. فرضية البحث مبنية على رؤية مستقبلية لإقامة تعاون عسكري بين العراق ودول الخليج

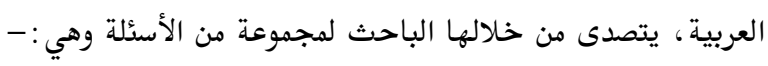

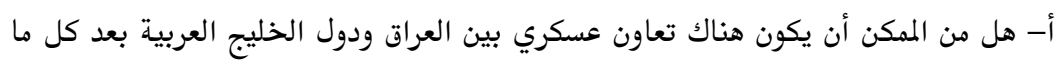

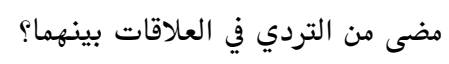

ب-ماذا سيقدم العراق (الجديد) لدول الخليج وماذا ستقدم هذه الدول للعراق في إطار هذا

$$
\text { التعاون؟ }
$$

ج-ما هي الأنماط المحتملة لهذا التعاون؟ التعاون؟

د- هل سيمر هذا التعاون بسلام دون مؤثرات خارجية عالمية وإقليمية؟ هادئ

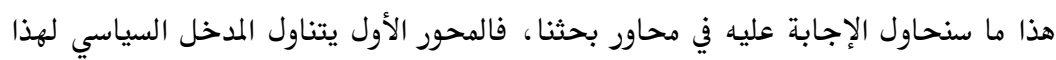

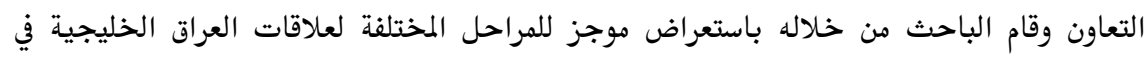

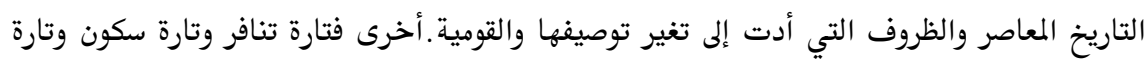

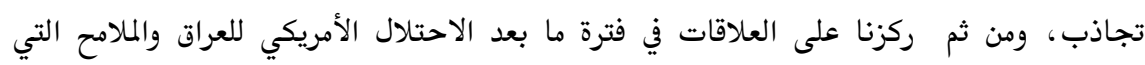

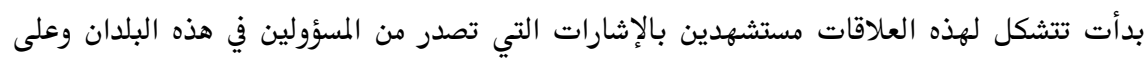
مختلف مستوياتهم، أما المحور الثاني والرئيس فتناول نماذج التعاون العسكري الممكن تحقيقها بين

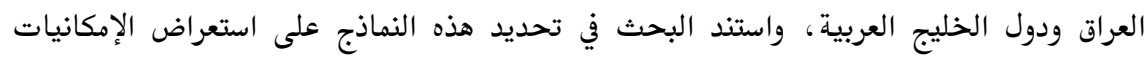




$$
\text { واثق محمد براك }
$$

الحالية للجيوش الخليجية من حيث التأليف والتسليح والتدريب والتجهيز والمؤسسات العلمية

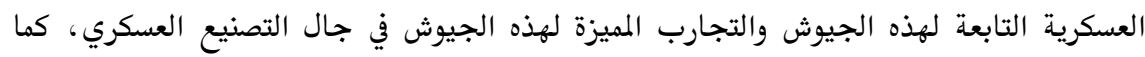
رأى الباحث أنه من المناسب التذكير بالاتفاقيات المبرمة بين حكومات هذه الدول المعنية بالتعاون

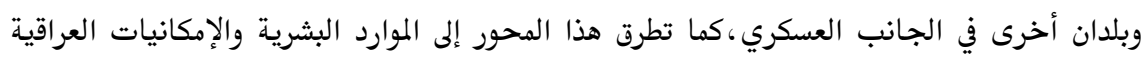

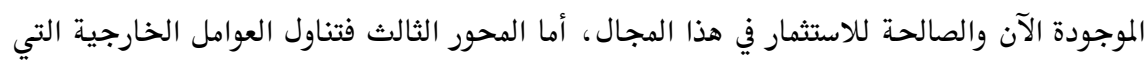

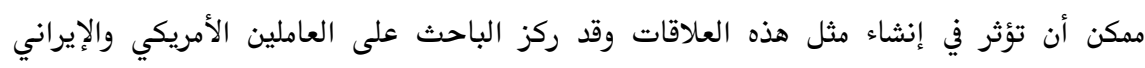

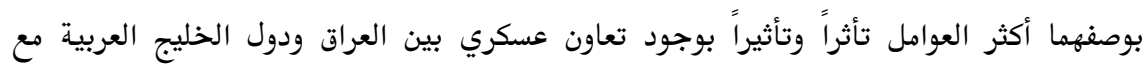
الأخذ بذظر الاعتبار بأن هذه المنطقة تهم جميع بلدان العالم. 


\section{ا- المدخل السياسي لإقامة العلاقات العسكرية بين العراق ودول الخليج العربية:}

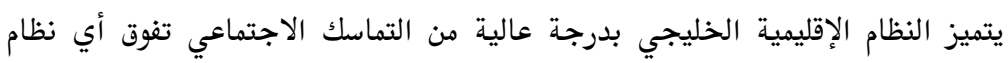

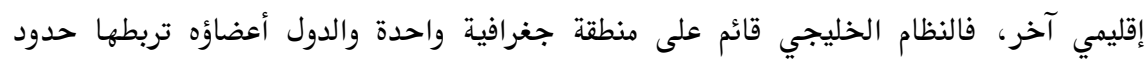

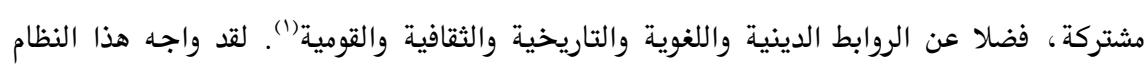
ومازال يواجه تهديدات عديدة بعضها فعلي وبعضها محتمل أوكامل، مصدرها التوترات والاضطرابات التي تحدث داخل وبين دول هذا النظام، وبين دول النظام والقوى الخارجية المؤثرة(()، فالعلاقات الدولية عبارة عن تفاعلات متداخلة متواصلة بين وحدات سياسية(الدول)

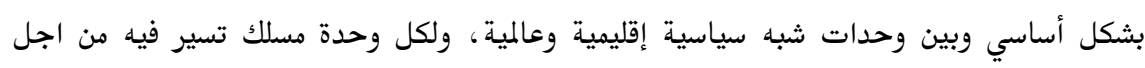

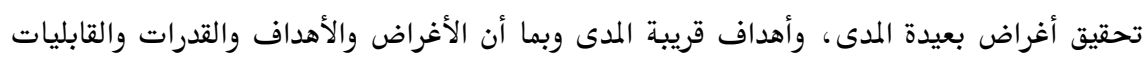

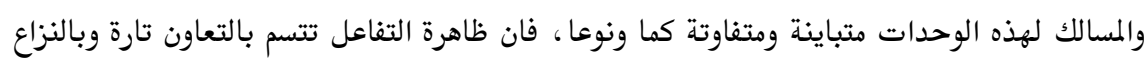
تارة أخرى، وقد يكون النزاع عند درجة واطئة فتنحصر في المجابهات الدبلوماسية وإثارة الخلافات

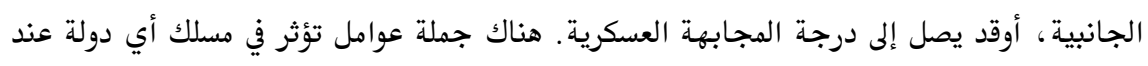

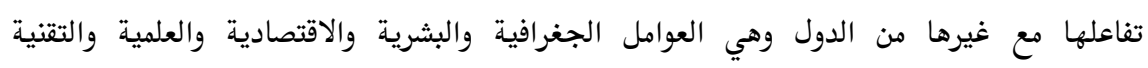

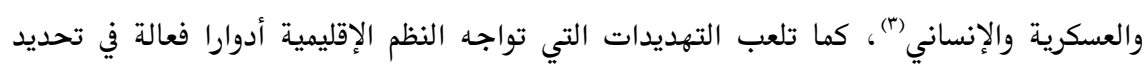
أنماط تفاعلات هذه النظم في اتجاه التعاون والتكامل (5). في النترة الممتدة من قيام النظام الجمهوري في العراق في الرابع عشر من تموز عام

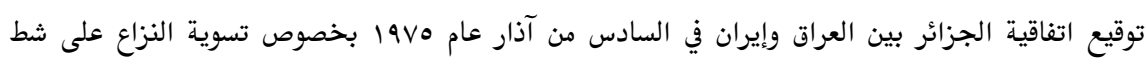

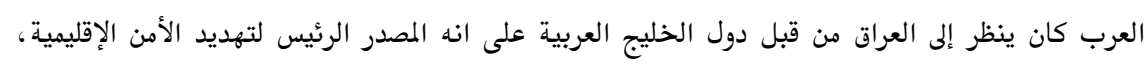

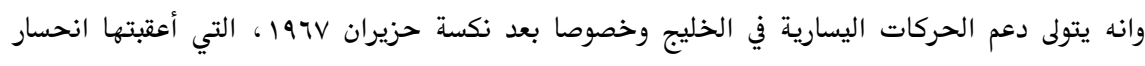

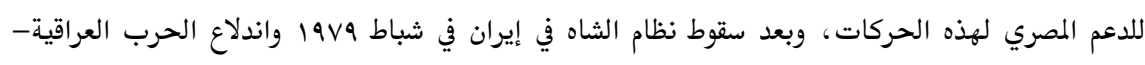

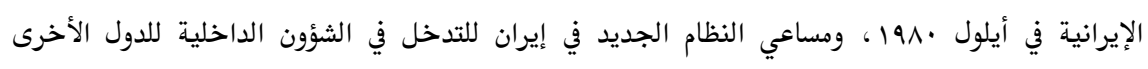

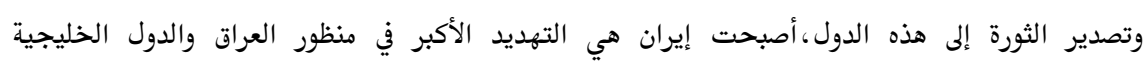

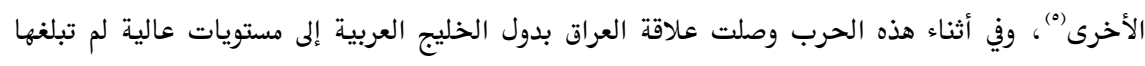

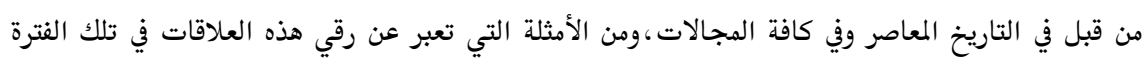


تخصيص ميناء (الكظيم) السعودي على شواطئ البحر الحمر، وميناء الشعيبة الكويتي على شواطئ الخليج العربي لاستخدامات العراق واحتياجاته سواء بالتصدير أوالتوريد بما فيها توريد الأسلحة والمعدات الحربية الفياء بمختلف أنواعها، وتدار هذه العمليات في ذلك الميناء من قبل مغارز إدارية (عسكرية ومدنية) عراقية كما أن القطع البحرية العراقية كانت لها أوامر مسبقة من قياداتها باللجوء إلى الموانئ والجزر الكويتية عند الضرورة

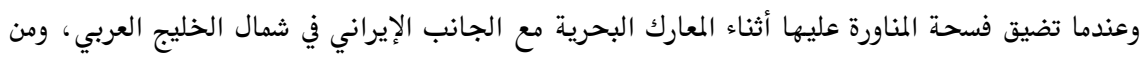
المؤكد أن هذه الأوامر استندت إلى تفاهمات سياسية بين العراق والكويت. بعد انتهاء الحرب العراقية الإيرانية في الثامن من آب 1911 تبنت الولايات المتحدة الأمريكية

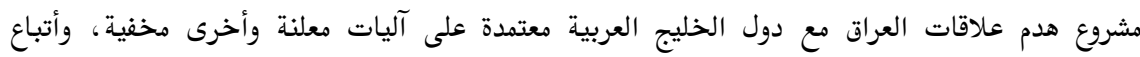
إستراتيجية(1)تهدف لفك التحالف الذي فرضته أخطار التهديد الإيراني بين العراق ودول الخليج العربية،

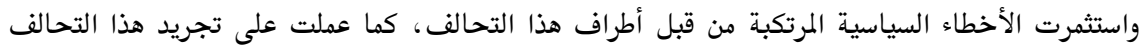

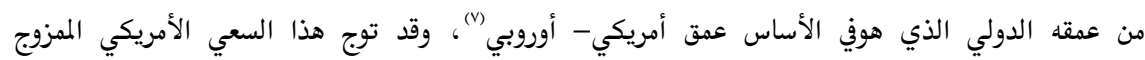

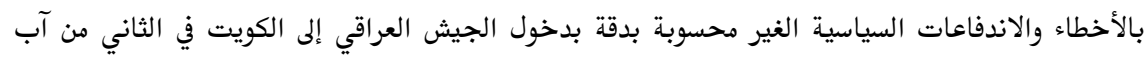

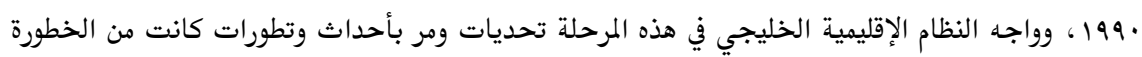
إلى درجة زلزلت مرتكزاته وأثرت بعمق في مجمل تفاعلاته التعاونية حيث تحولت الصداقة إلى عداوة

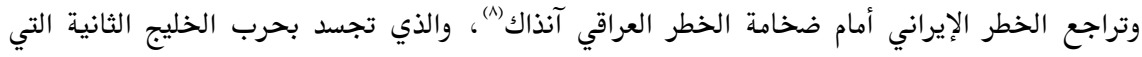
أعقبت دخول العراق للكويت، الحدث الذي يعد جوهر القضايا الخلافية بين العراق ودول مجلس التعاون لدول الخليج العربية في التاريخ المعاصر.

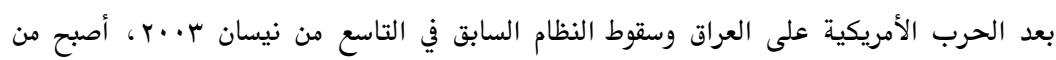

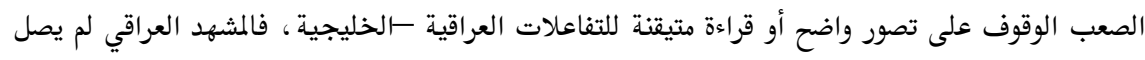

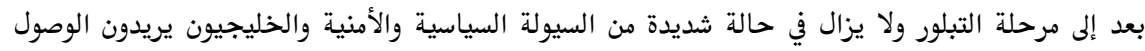
إلى قناعة بان ما يجري في العراق ليس على حسابهم ولا يشكل تهديدا لأدوارهم الإقليمية، وفي هذا الصدد

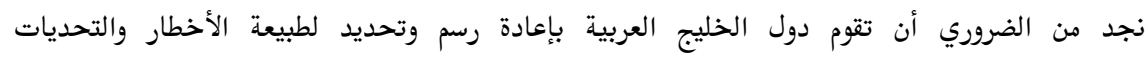

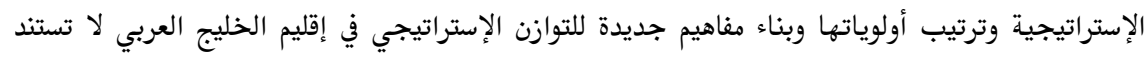

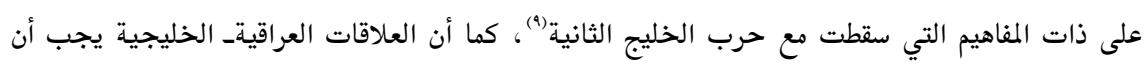

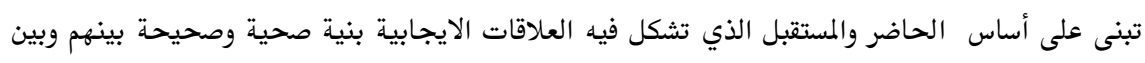

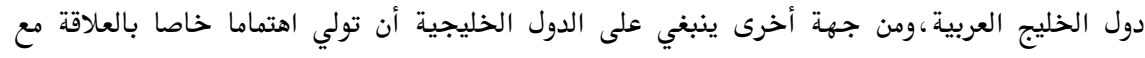

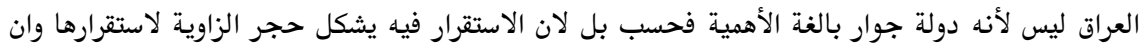


قوته هي أيضا قوة لها لذلك فان إعادة التوازن لإقليم الخليج والذي تحتاجه دول الخليج العربية أكثر من

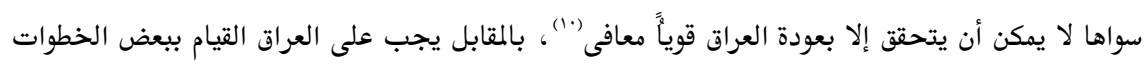

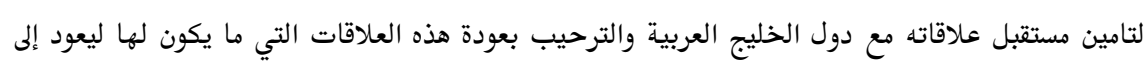
أحضان المذطقة ثابت الجنان بعد فترات شوهت سياساته وتوجهاته هوأحوج ويجب أن تميل مواقفه إلى تهدئة الأمور وتحسين الصلات (11).

إن التصور الخليجي للوضع العراقي بعد الاحتلال الأمريكي الذي يمكن بوجوده بناء علاقات

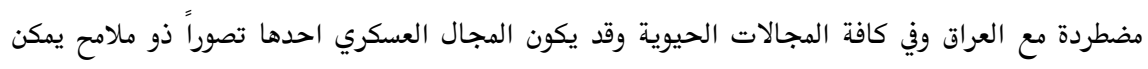
تحديدها من وجهة نظر دول الخليج العربية بوضوح فقد ورد في تقرير السياسة الخارجية للأمانة العامة

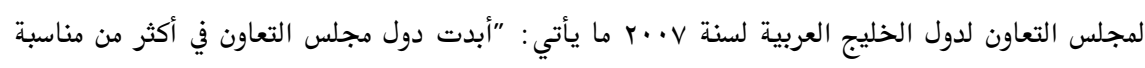

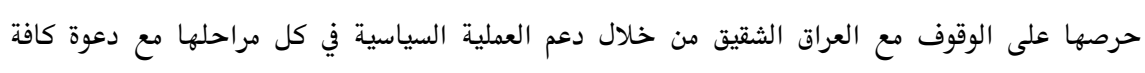
القوى العراقية إلى تشكيل حكومة وحدة وطنية تمثل كافة أطياف الشعب العراقي الثنية والدينية دون تميز وتعبر عن تطلعات مواطني ومحيطه العربي في إرساء دعائم عراق آمن ومستقر وموحد قادر على معاودة دوره

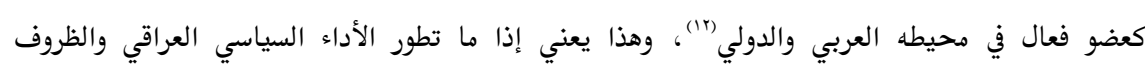
المحيطة به ووصل إلى مرحلة مطابقة للشروط الخليجية لتعميق العلاقات مع العراق وتنويعها وتطويرها، يمكن بناء رؤية مستقبلية ايجابية لهذه العلاقات بمختلف مجالاتها ومن ضمنها العسكرية، فالتجارب التهاب السابقة تشير إلى أن التجمعات الإقليمية يمكن أن تلعب دوراً في تحقيق تعاون أفضل وخاصة في المجال

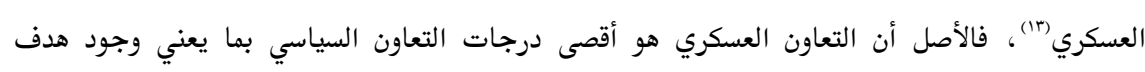

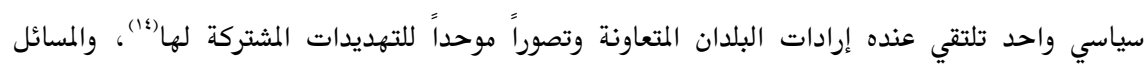
العسكرية تتشابك (في ظل الظروف والأحوال الحديثة) مع المسائل السياسية والاقتصادية والاجتماعية

والتقنية ومن المشكوك فيه أن يستطيع احد أن يتحدث عن (الإستراتيجية العسكرية) خالصة لوحدها (10).

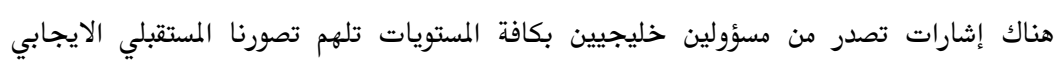
لطبيعة العلاقة بين العراق ودول الخليج العربية وإمكانية تطورها لتصل إلى حد التعاون العسكري منها

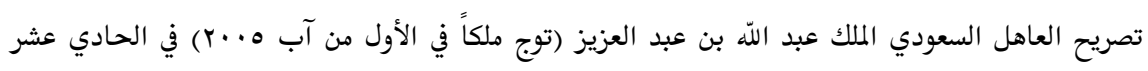
من كانون الثاني ؟ ·. خ خلال استقباله وفد حكومي عراقي وكان حينئذ وليا للعهد حيث صرح (ان المملكة العربية السعودية والعراق في قارب واحد وأي سوء يمس هذا القارب يمس الجانبين)(17)، وتصريح الأمير

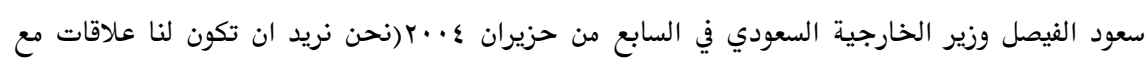


العراق لان مصالحنا مشتركة)(1)، وتصريح الأمير عبد الرحمن بن عبد العزيز نائب وزير الدفاع والطيران

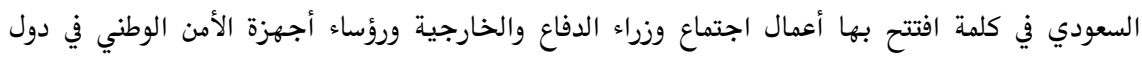

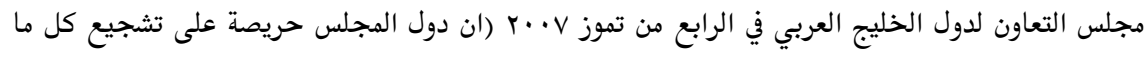

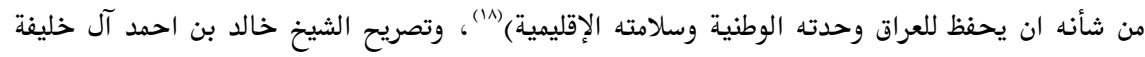

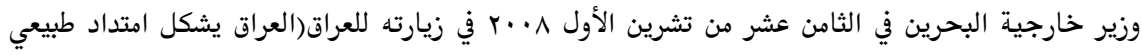

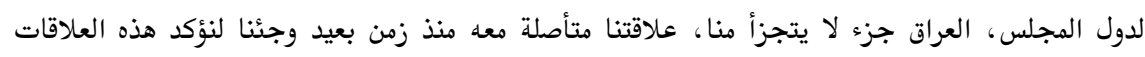

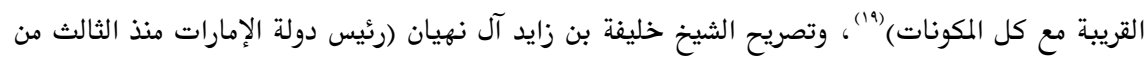

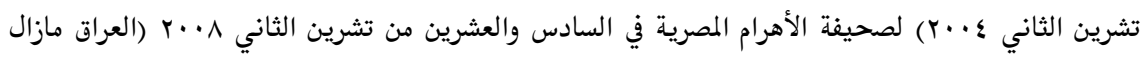
يحتاج إلى المزيد من الجهود حتى يستعيد عافيته ودوره الإقليمية ومكانته كعامل فاعل من عوامل الاستقرار

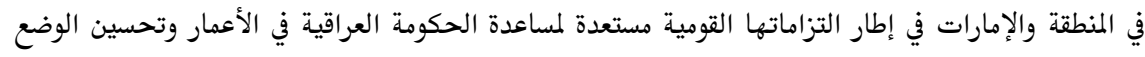

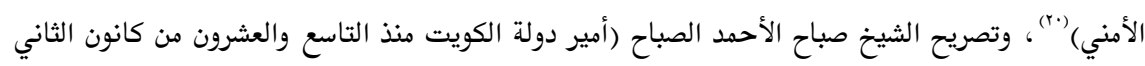

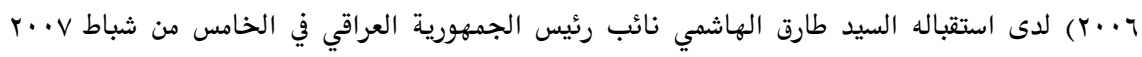

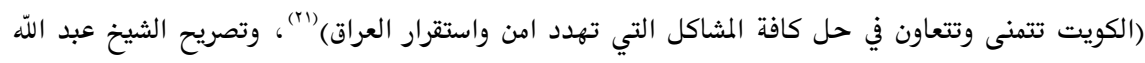

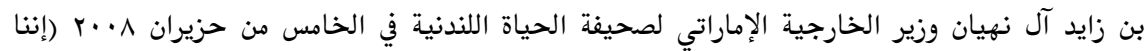
ننظر إلى العراق كشريك ههم للإمارات في المنطقة ونتطلع إلى أن يكون شريكاً لمجلس التعاون الخليجي وان

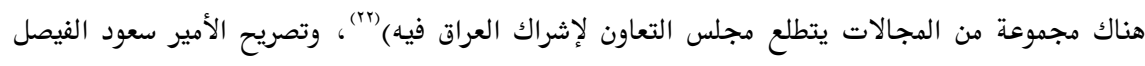

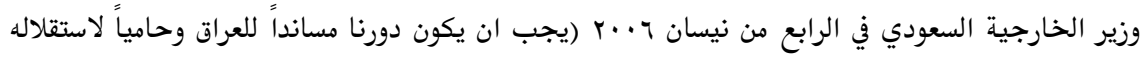

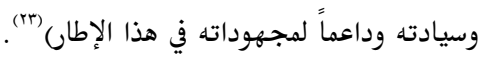
يبشر الانفتاح الدبلوماسي العربي على العراق بعودة عربية هنتظرة لن تصل إلى طور النضج والاكتمال من دون استكمالها بخطوات أخرى سياسية واقتصادية واجتماعية مما يتطلب إستراتيجية عربية تجاه العراق تستند إلى رؤية ثاقبة للشهد العراق الراهن،كما ان هذه العودة تستحق موقف عراقي ايجابي يغترض

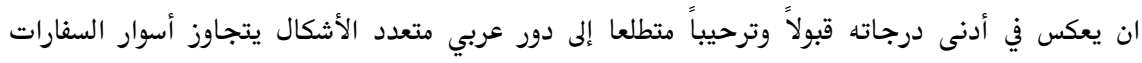

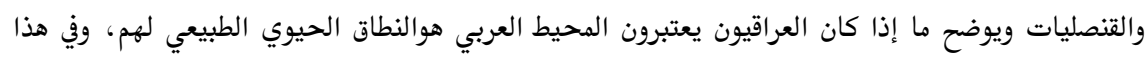

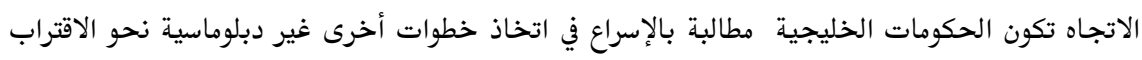

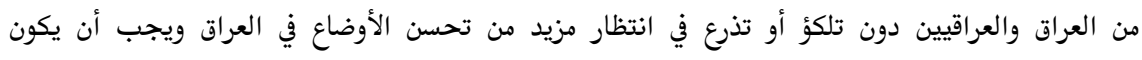

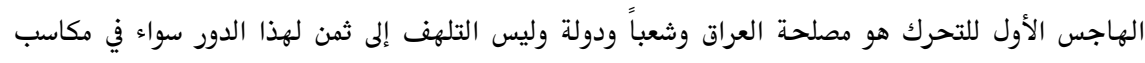
اقتصادية أومصالح إستراتيجية أو غير ذلك لان العراق على مشارف مرحلة مغايرة ليس فقط عما كان عليه 
قبل الغزو الأمريكي، بل أيضاً عن سنوات الاحتلال الخمس الماضية ويجب على الرؤية السياسية الخليجية

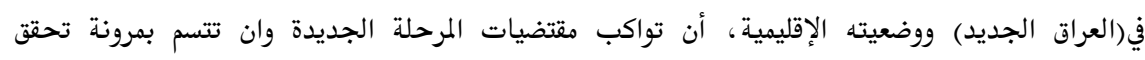

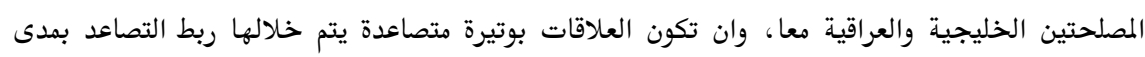

الاستقرار والتقدم في الوضع العراقي الداخلي وتماسك الدولة ووحدتها وعمق ارتباطها بالمحيط العربي أعجان.

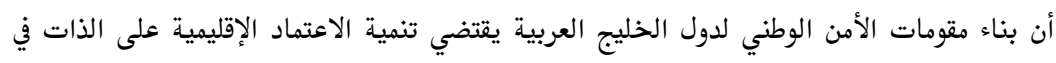

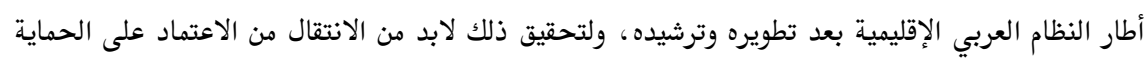

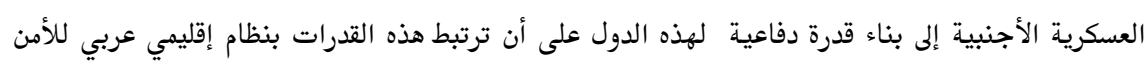

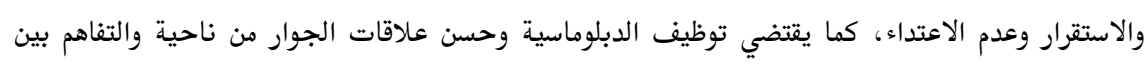

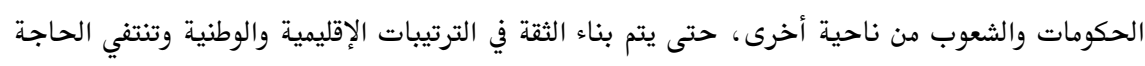

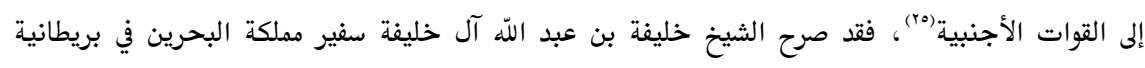

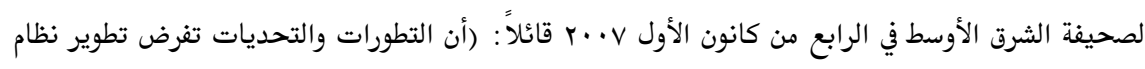

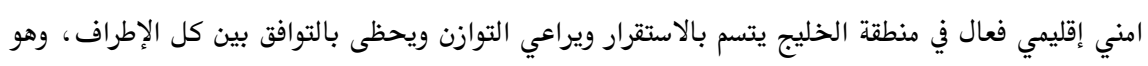

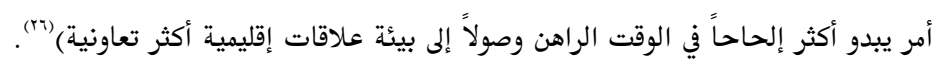

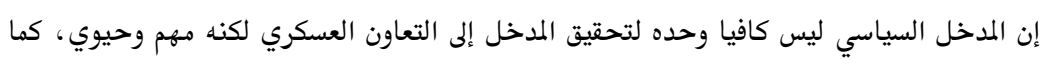

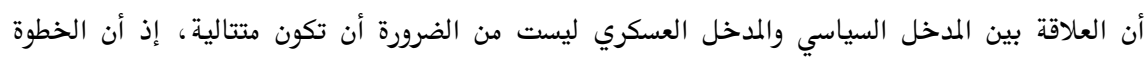

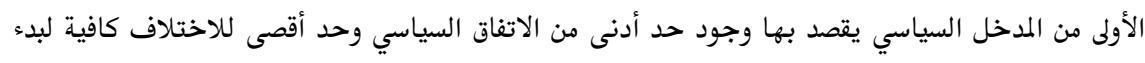

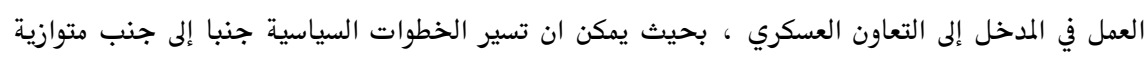

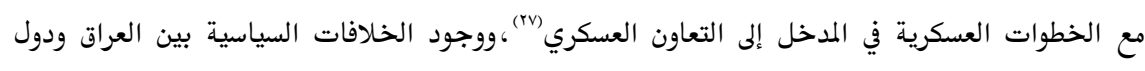

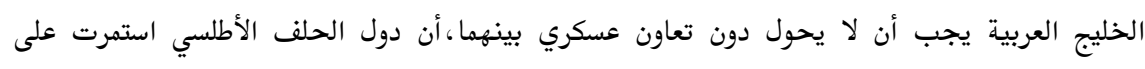

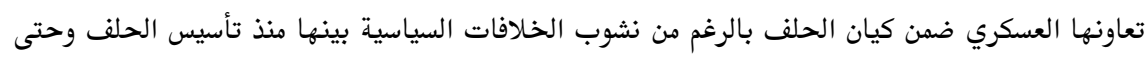

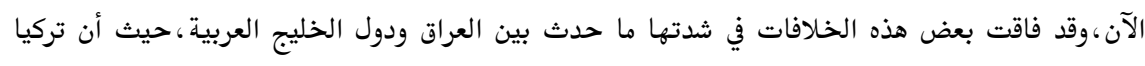

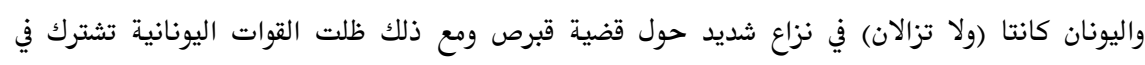

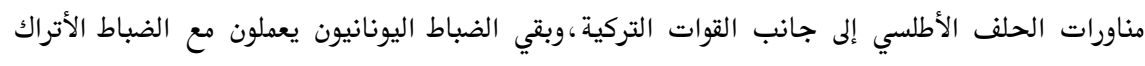

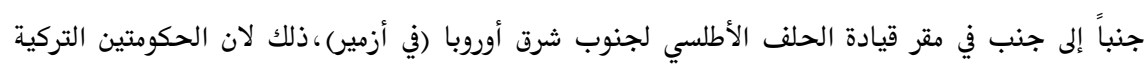

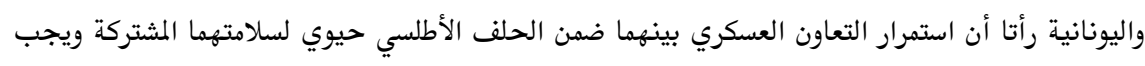

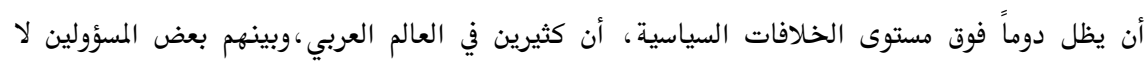


يقدرون أهمية التعاون العسكري،فمثل هذا التعاون ليس بأمر كمالي،فبالنسبة للدول الخليجية والعراق هو

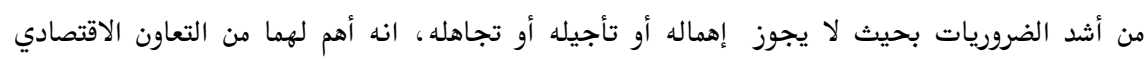

\section{r- النماذج الممكنة للعلاقات العسكرية بين العراق ودول الخليج العربية}

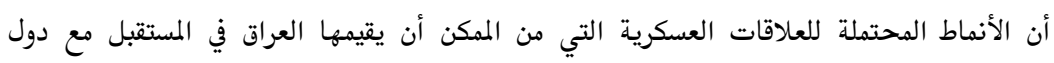

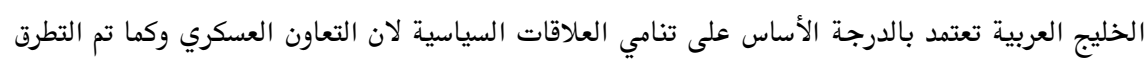

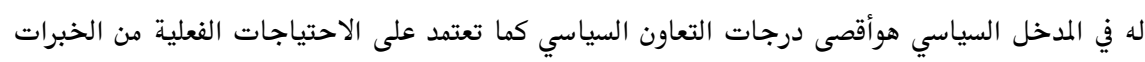

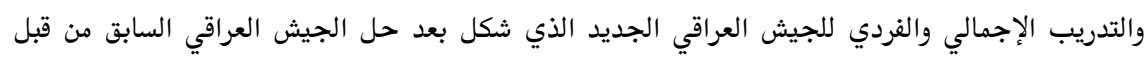

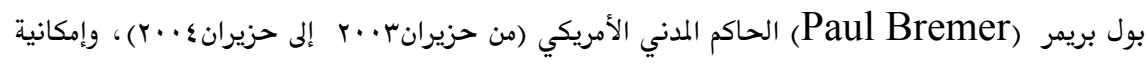

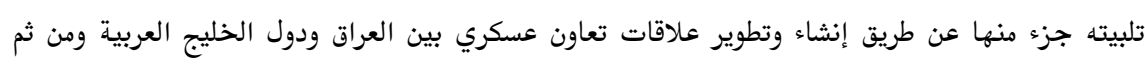

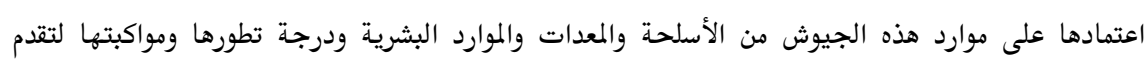

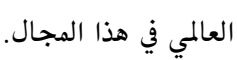

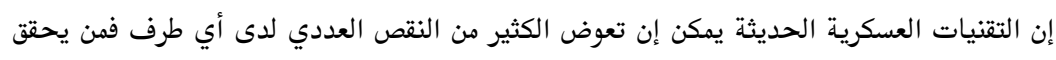

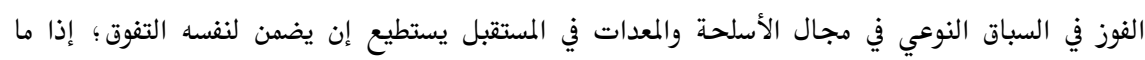

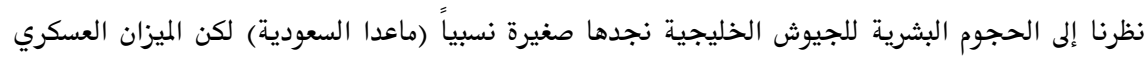

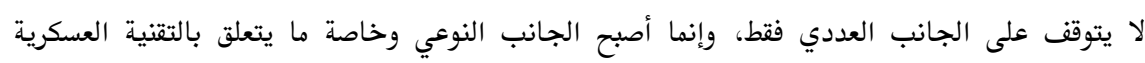

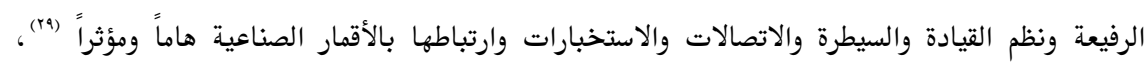

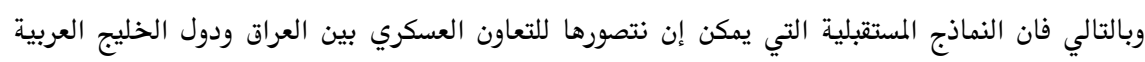

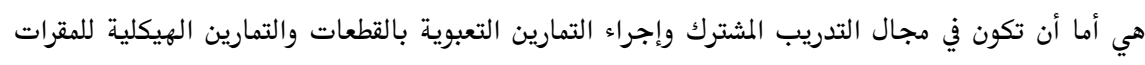

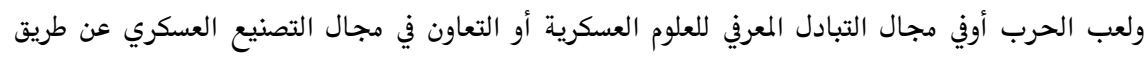

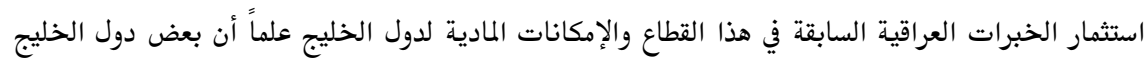

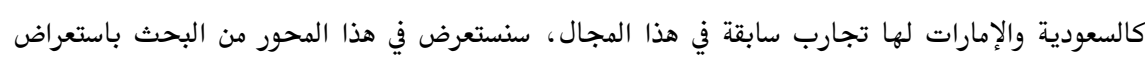
الخيارات المفتوحة للتعاون العسكري.

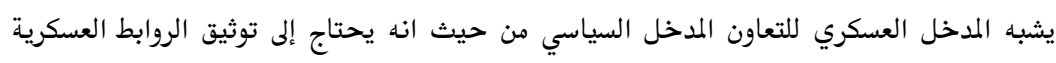

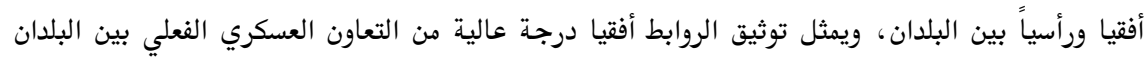

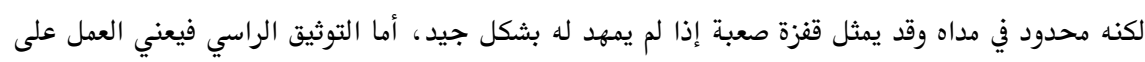


توحيد السياسات والتصورات العسكرية مثل توحيد التنظيم والتسليح والتدريب وبناء عقيدة عسكرية مشتركة وتبادل المعلومات عن مصادر التهديدات المختلفة، ووضع أسس موحدة للعلم العسكري،ودراسة مسارح العمليات المتوقعة وإقامة صناعة عسكرية مشتركة، كل هذه الخطوات أو بعضها فقط تصنع أسساً متينة

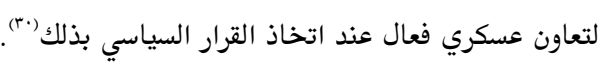
أ- التعاون العسكري في مجال التدريب المشترك.

أن الجيش العراقي الجديد وبرغم أن الغالبية العظمى من منتسبيه وخصوصاً الضباط هم من الجيش السابق وبرغم الحجم العددي الكبير الحالي لوحداته وإفراده، إلا انه بالمقاييس والمعايير العالمية للجيوش يعد الآن من الجيوش الناشئة والتي تحتاج إلى خبرات ومهارات مكتسبة سواء على لى المستوى الإجمالي (الوحدات) أو المستوى الفردي(الضباط والمراتب) والتي لا يمكن توفرها إلا بالاحتكاك والتدريب المشترك بالجيوش الأخرى لكي تصل إلى مستوى يجعلها قادرة على الدفاع عن البلد أمام التهديدات المحتملة، هنالك تعهدات من قبل الولايات المتحدة الأمريكية ودول منظمة حلف شمال الأطلسي (NATO) للعراق بالمساهمة الفعالة في بناء وتطوير الجيش العراقي وقد تكون هذه الالتزامات في حال تنفيذها ذات فائدة عظيمة في تطوير هستوى الأداء للضباط والمراتب العراقيين بشكل فردي ولكن على مستوى الوحدات يبقى الخيار الخليجي هو الأنجع، فالضابط العراقي لا يحتاج إلى استخدام لغة أخرى للتعاون مع ضابط في جيش عربي أخر كما إن الاتصال الجغرافي يسمح بالانتقال لهذه الجيوش بكل وسائل النقل المعروفة، فوحدة القيم والعادات تسهل كثيرا من تحقيق حاجات الجيوش العربية في حال تعاونها(1). من الضروري قبل تبني هذا النمط من العلاقات العسكرية التعرف على البناء الحالي لجيوش دول الخليج العربية بالإضافة إلى

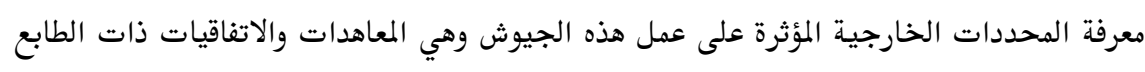
العسكري والأمني المبرمة بين بلدان الخليج العربية والبلدان الأخرى. تعد القوات المسلحة السعودية اكبر قوة عسكرية بدول مجلس التعاون الخليجي، وتشمل القوات البرية والحرس الوطني والقوات البحرية والقوات الجوية ، تتألف القوات البرية من ل.. Vo.

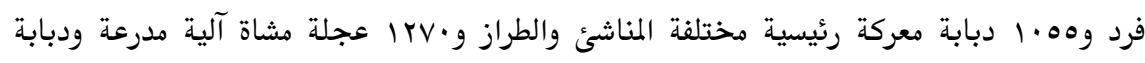

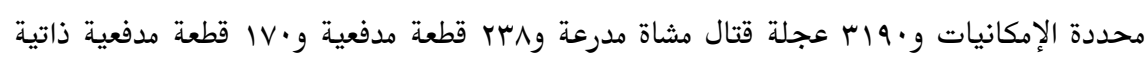


الحركة و.r راجمة صواريخ و.ا قاذفات صواريخ أرض-أرض GSS-2 و.0.r سلاح موجه

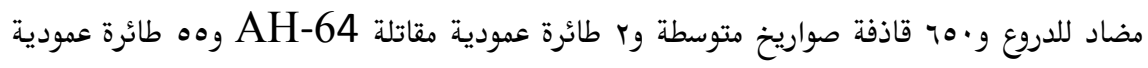

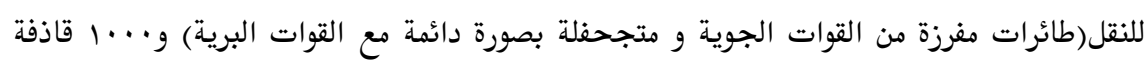

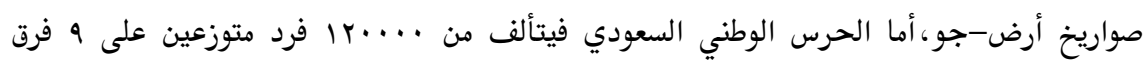

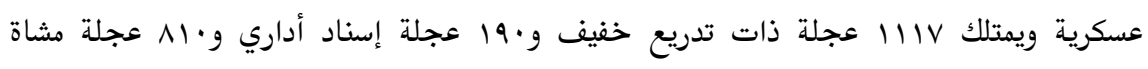

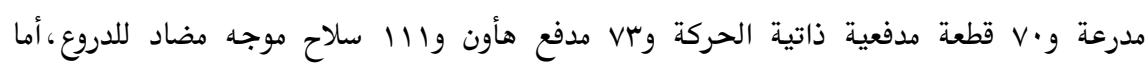

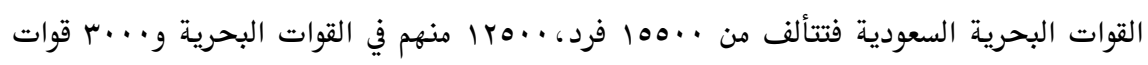

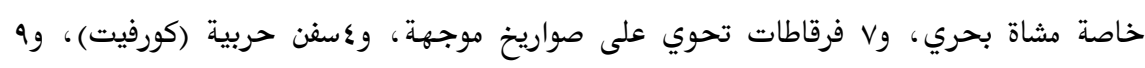

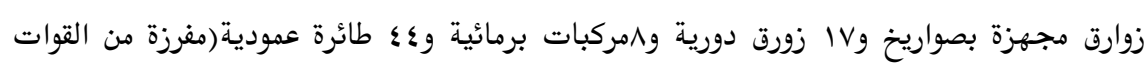

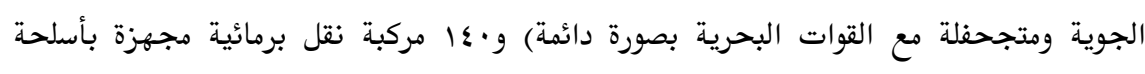

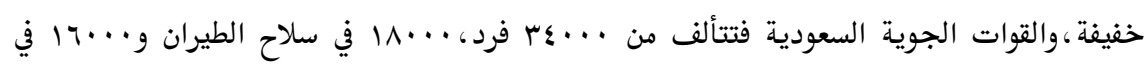

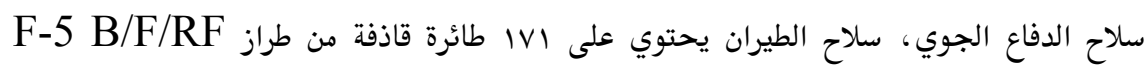

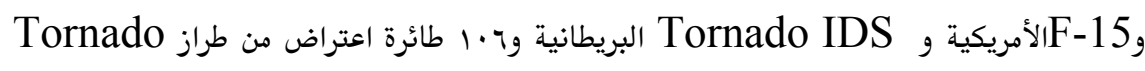

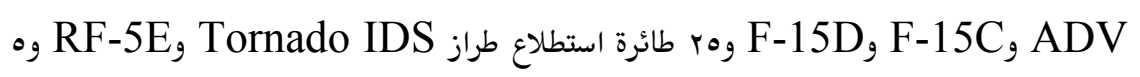

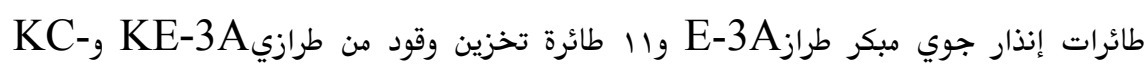
130H وهـ طائرة نقل من طراز

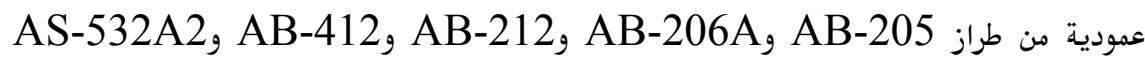

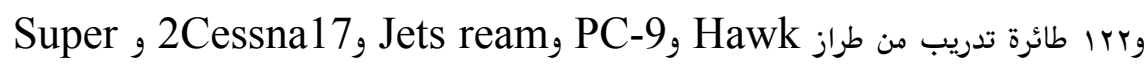

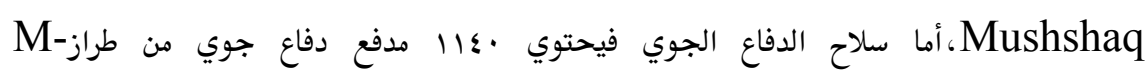
L/7 40mm, 35mm, AMX-30SA 30mm, 163Vulcan 20mm Crotale, MM-23Bg Shahine وع طبه صاروخ ارض-جومن PAC-2/Patriot, Mistral, Redeye, Stinger/FIM-92A Avenger, 
أولاً. اتفاقيتا (إنشاء قاعدة جوية في الظهران) و(المساعدة المتبادلة للدفاع)، وقعتا في مكة وجدة في الثامن عشر من حزيران 1901 بين ريموند.أ.هير سفير أمريكا في السعودية وفيصل بن عبد وليد

$$
\text { العزيز وزير الخارجية(في حينها). }
$$

ثانياً. اتفاقية(بعثة التدريب العسكري الأمريكي )وقعت في مكة وجدير وجدة في السابع والعشرين من حزيران/19 بين السفير الأمريكي ريموند.أ.هير والأمير مشعل وزير الدفاع والطيران.

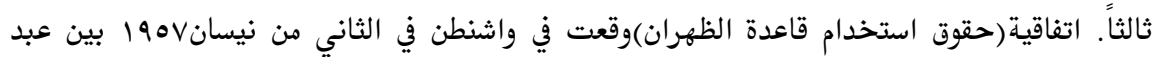
اللّ الخيال سفير السعودية في أمريكا وجون فوستر دالاس وزير خارجية أمريكا.

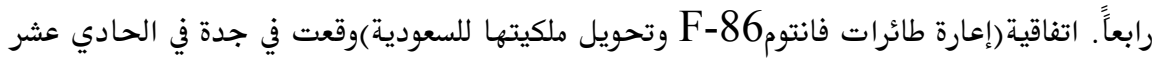
من تشرين الثانيو1970 بين السفير الأمريكي باركر.تي.هارت وعمر السقاف وزير الدولة للشؤون الخارجية السعودي.

خامساً. اتفاقية(إنشاءات عسكرية من قبل سلاح المهندسين الأمريكي) وقعت في جدة في الرابع والعشرين من مايسه9919 بين السفير الأمريكي باركر.تي.هارت وعمر السقاف وزير الدولة للشؤون الخارجية السعودي. سادساً. اتفاقية (امتيازات وحصانات العاملين الأمريكان في برنامج الصيانة والتدريب لطائرات

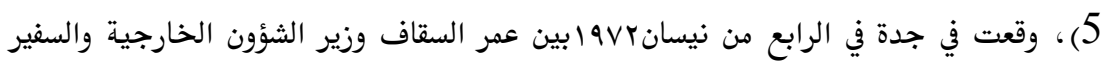
الأمريكي.

سابعاً. اتفاقية (المساعدة العسكرية الأمريكية) وقعت في جدة في الخامس عشر من مايسو 19VY.

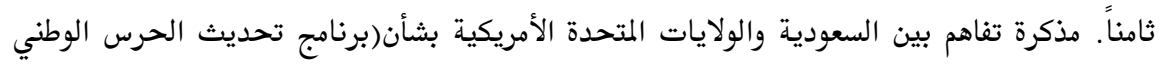

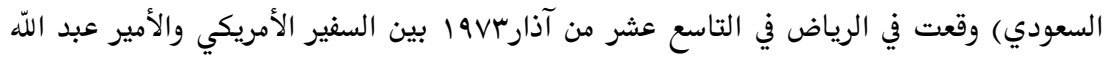

$$
\text { بن عبد العزيز رئيس الحرس الوطني. }
$$
تاسعاً. بيان مشترك حول(التعاون العسكري السعودي-الأمريكي) وقع في واشنطن في الثامن من لندئ حزيران؟19Vا بين وزير الخارجية الأمريكي هنري كيسنجر ووزير الداخلية السعودي فهد بن فين عبد العزيز. 


$$
\text { واثق محمد براك }
$$

عاشراً. اتفاقية(الدفاع المشترك) وقعت في الرياض في السابع والعشرين من شباطvل19 بين السفير

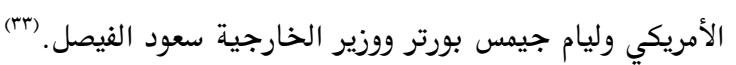

أما الجيش الإماراتي فتشير التقارير إلى انه أحرز إنجازات كبيرة في تجدئ لجديد لهديد مقدراته

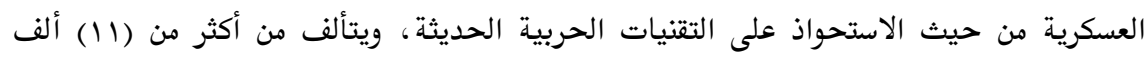

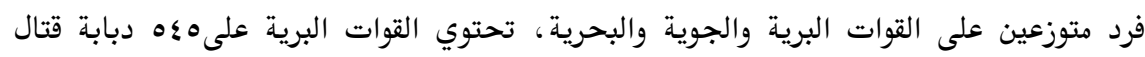

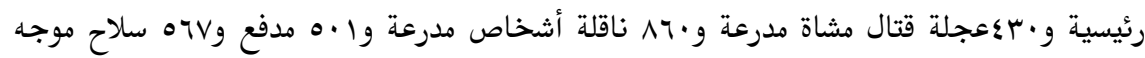

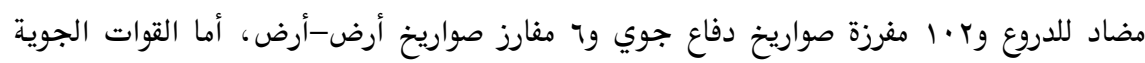

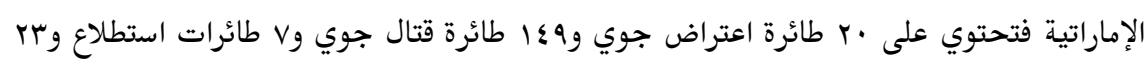

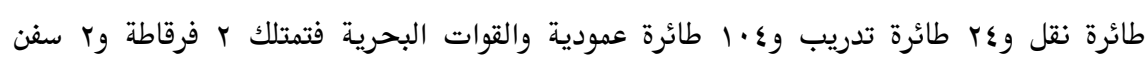

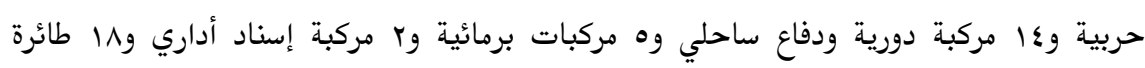

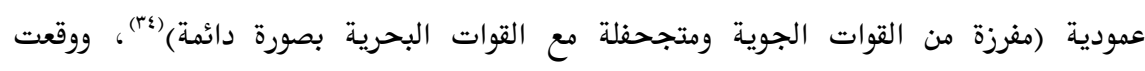

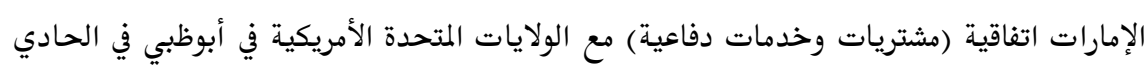

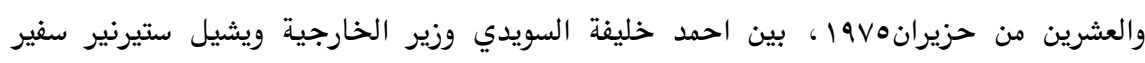

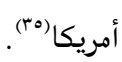

يصنف الخبراء العسكريين القوات المسلحة العمانية على أنها من أفضل الجيوش في المنطقة

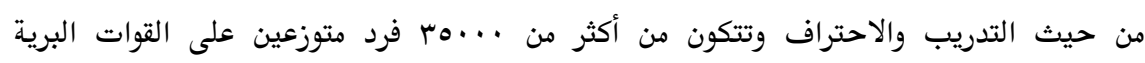

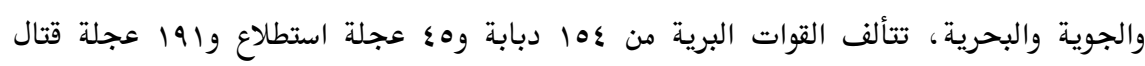

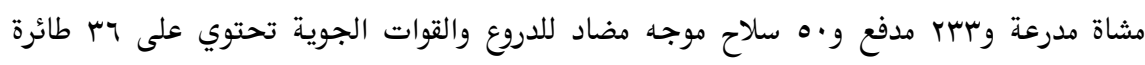

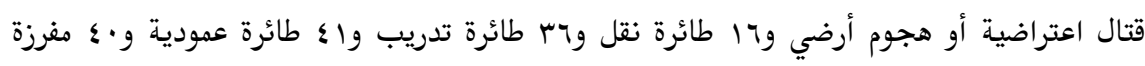

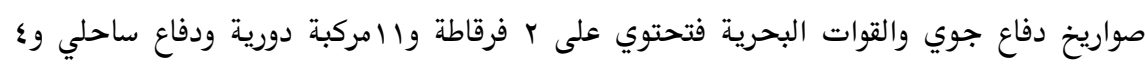
مركبة إسناد أداري("(r)، وهناك اتفاقية (تسهيلات عسكرية) يتكون الجيش القطري من . .01 فرد يشمل القوات البرية والقوات البحرية والقوات الجوية

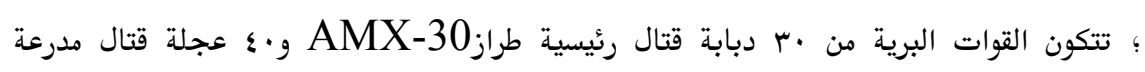

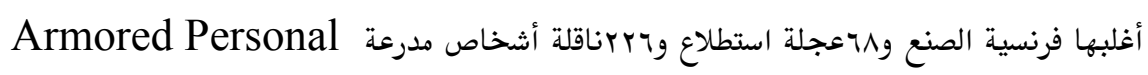

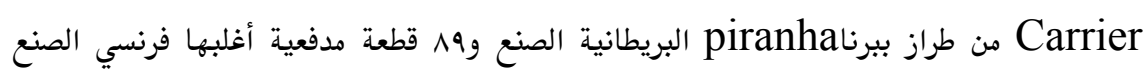




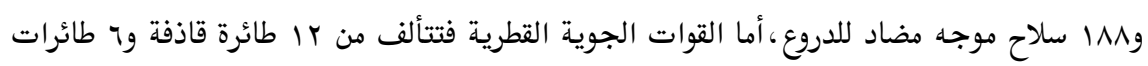

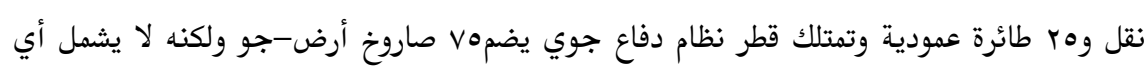

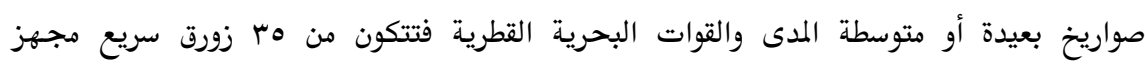

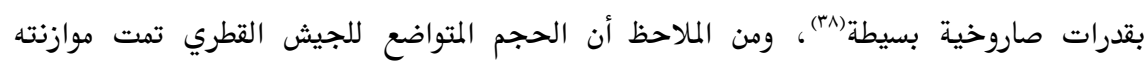

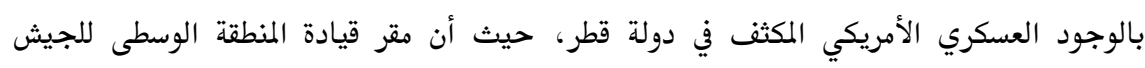
الأمريكي في قاعدة السيلية في قطر.

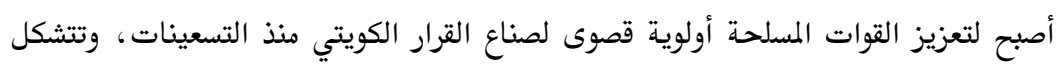

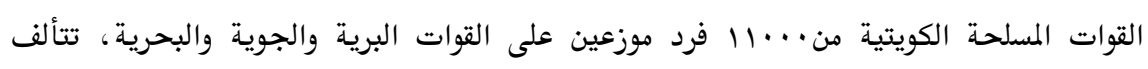

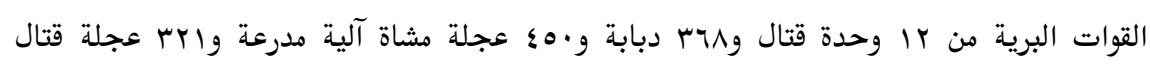

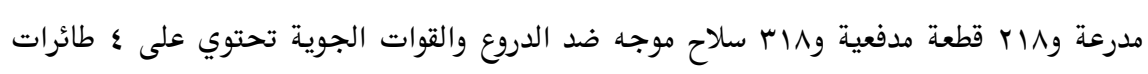

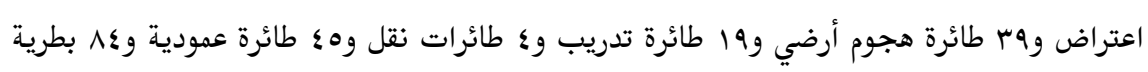

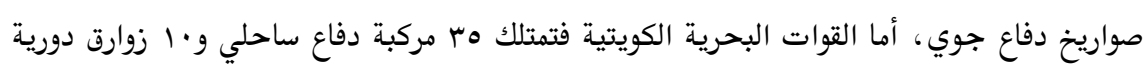

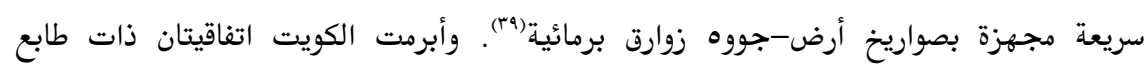

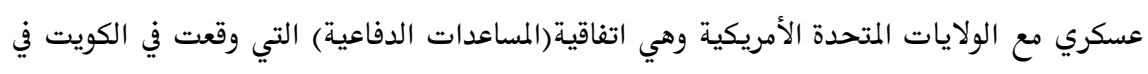

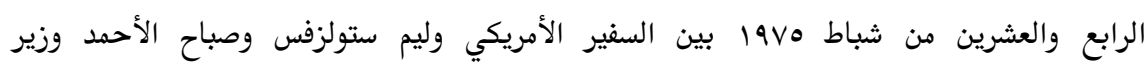

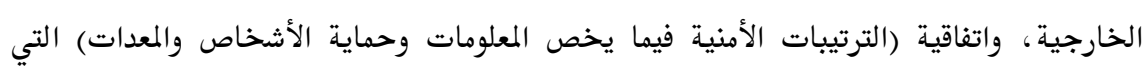

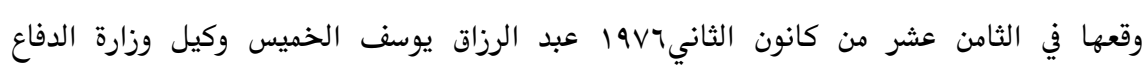

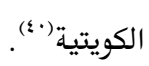

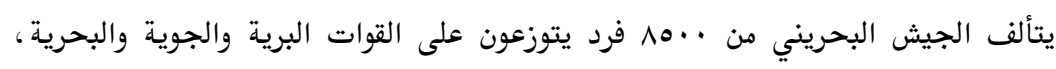

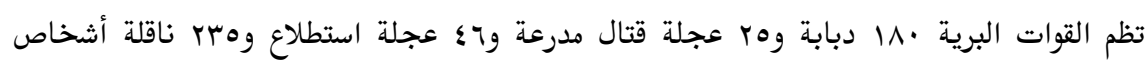

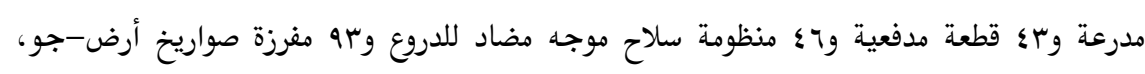

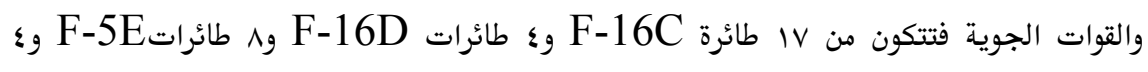

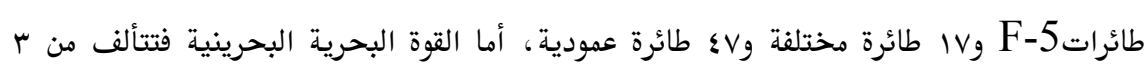

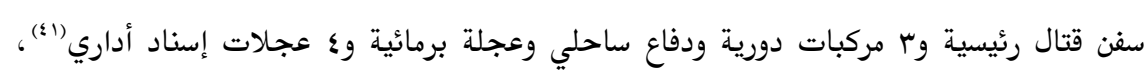


وعقدت البحرين اتفاقيتان في المجال العسكري مع أمريكا وهي اتفاقية (تأجير قاعدة الجفيرالتي

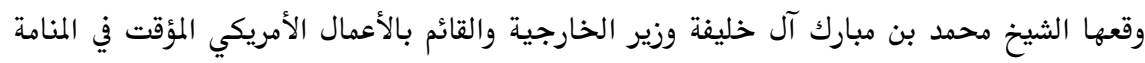

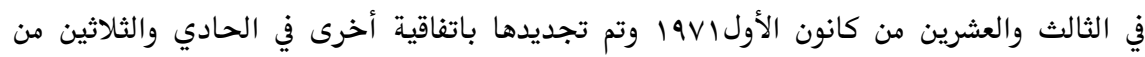
تموز9V1ا وقعت بين محمد بن مبارك آل خليفة وزير الخارجية البحريني والسفير الأمريكي جوزيف دبليوتوينام، والاتفاقية الأخرى هي(وحدة الدعم الإداري) وقعت في المنامة في الثامن والعشرين من حزيران 19VV بين محمد بن مبارك وزير الخارجية ووات تي كلوفيرس السفير

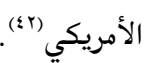

\section{ب- التعاون في مجال العلوم العسكرية.}

من المعروف ان المؤسسات العلمية العسكرية العراقية السابقة كأكاديمية البكر للدراسات

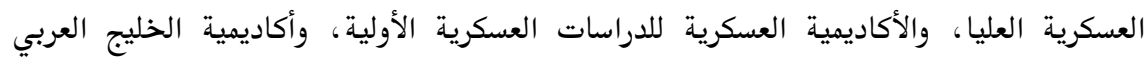

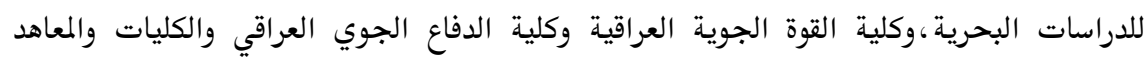

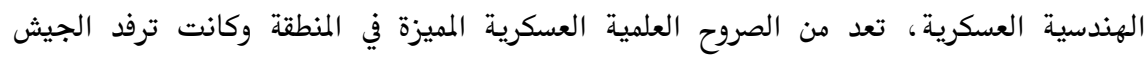
العراقي والجيوش العربية والجيوش الصديقة بضباط وقادة أكفاء ذوي مستويات راقية في العلوم

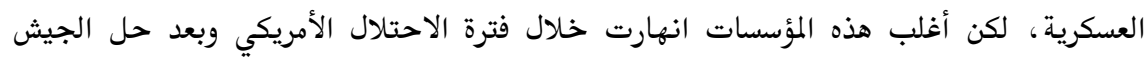

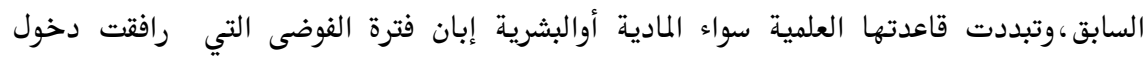

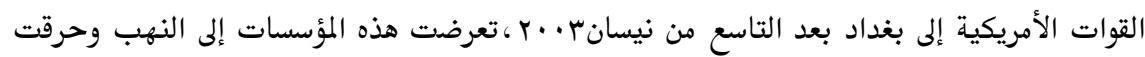

$$
\text { جميع المراجع العلمية والبحوث التي كانت تحتويها. }
$$

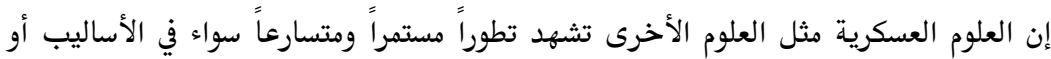
التقنيات والمعدات المستخدمة أو تطوير التنظيم والهيكلية وطرق ووسائل التدريب، والمؤسسات

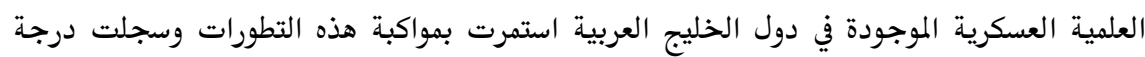
مقبولة من الاستجابة للمتغيرات في هذا القطاع،ومن المفيد إن تحاول المؤسسات العلمية العسكرية

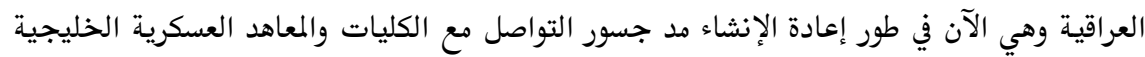

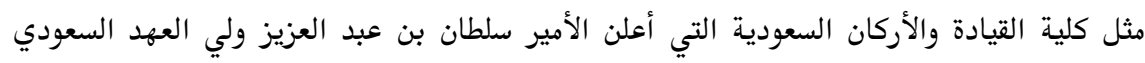
خلال رعايته حفل تخرج الدورة بr فيها والتي تزامنت مع تخرج دورة التخطيط في المستوبين 
الإستراتيجي والعمليات في نغس الكلية في السابع عشر من حزيرانV·•r،أعلن عن إنشاء كلية

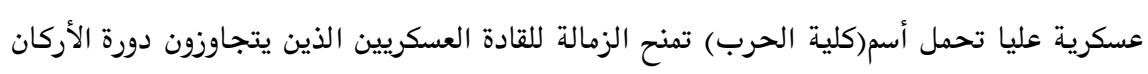

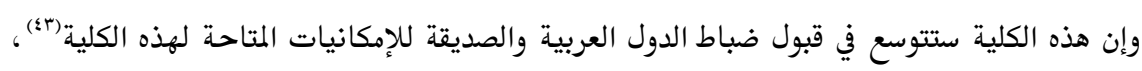

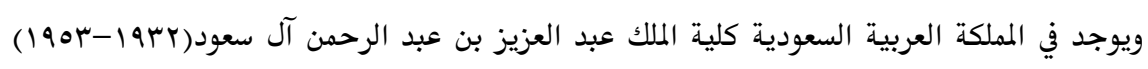

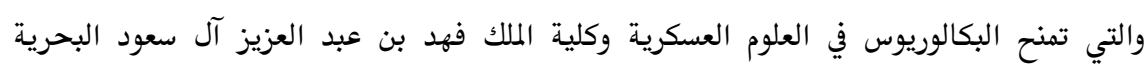

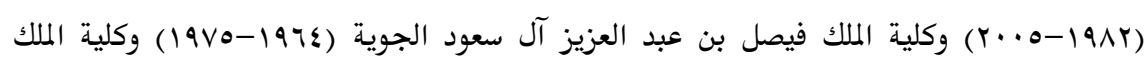

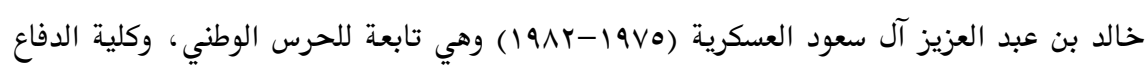

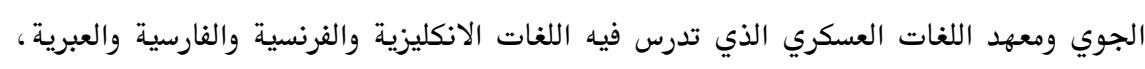

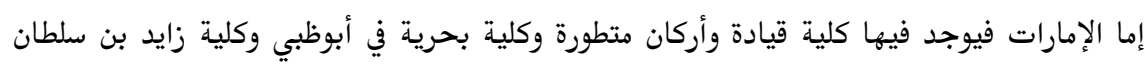

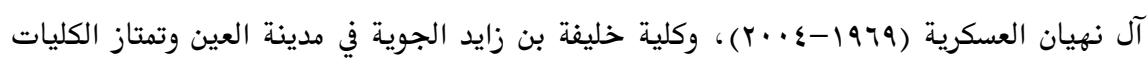

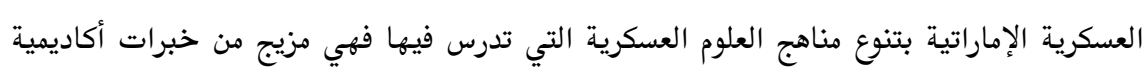
ساند هيرست الملكية البريطانية SAND HURST ROYAL MILITARY ACADEMY العسكرية الفرنسية (سان سير) ، إما عمان فتمتلك كلية متخصصة بالحرب الالكترونية وهي كلية

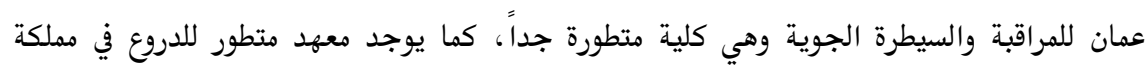
البحرين وهي هدرسة الدروع الملكية التي تحتوي على مشبهات تدريبية ونماذج مقطعية للدبابات

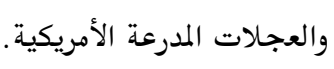

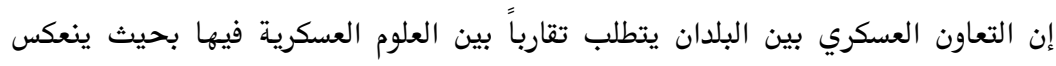

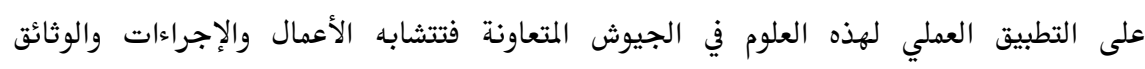

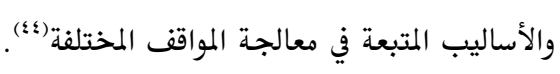
ج-التعاون في مجال التصنيع العسكري

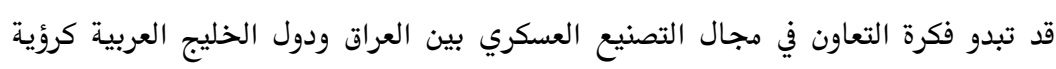

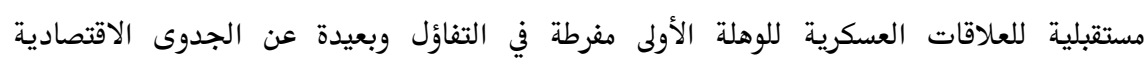

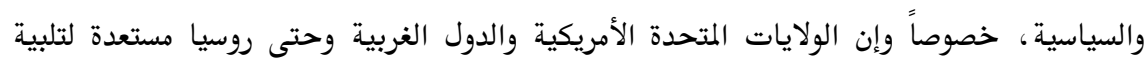


واثق محمد براك

الاحتياجات العسكرية لدول الخليج والعراق(الجديد) وتزويدهم بمنتجات عسكرية من الأسلحة

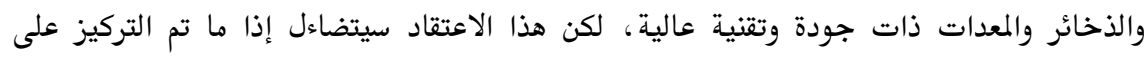
الاعتبارات الاقتصادية لإقامة مثل هذه الصناعات خصوصاً والعالم الآن يمر بأزمة اقتصادية حادة، وهذه الاعتبارات :

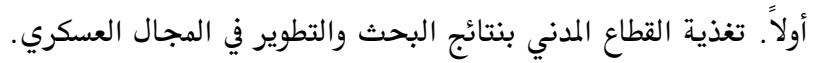
ثانياً. استيعاب واستغلال فائض العمالة. ثالثاً. تنشيط الصناعات المتصلة بقطاع الدفاع إنتاج الصلب والكيميائيات.

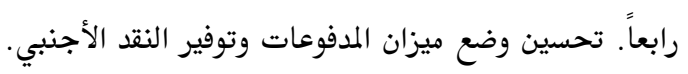
خامساً. زيادة إسهام القيمة المضافة المحلية، وبالتالي تحسين الناتج المحلي الإجمالي. سادساً. خفض تكلفة الوحدة من خلال توسيع نطاق الإنتاج.

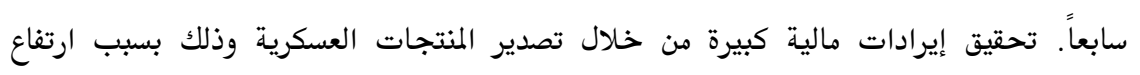
هامش الربح في بيع هذه المنتجات في الأسواق العالمية. ثامناً. اكتساب الخبرة والمهارات الفنية.

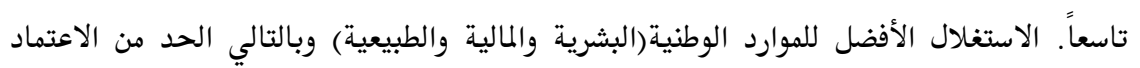
على العالم الخارجي والانكشاف إلى التقلبات الدولية(ه).

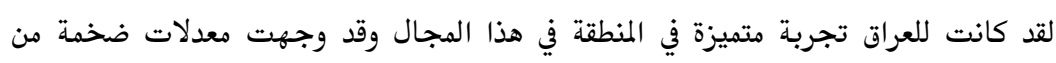

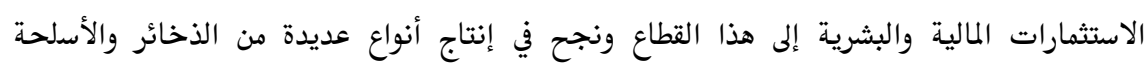

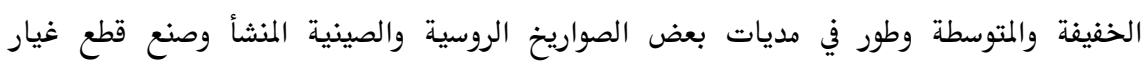

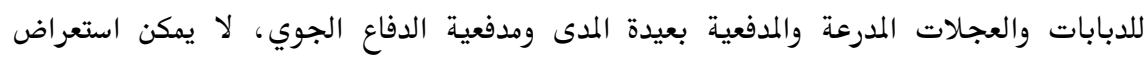

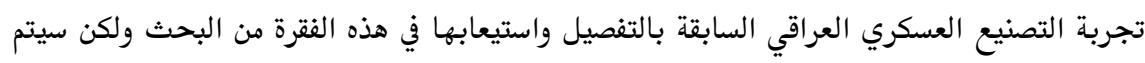
إبراز ما تبقى من هذه التجربة والتي لا تزال صالحة للاستثمار وهي الموارد البشرية.

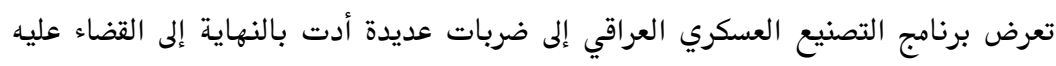

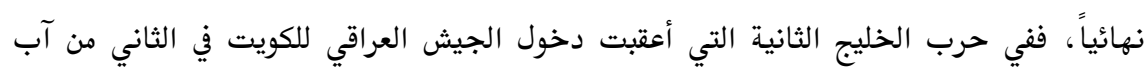
199. قوات التحالف الذي قادته الولايات المتحدة الأمريكية ضد العراق، ومن نهاية هذه الحرب ولغاية إنهات 
الغزو الأمريكي للعراق في العشرين من آذار ب... تعرض هذا البرنامج إلى تدمير مذظم من قبل فرق

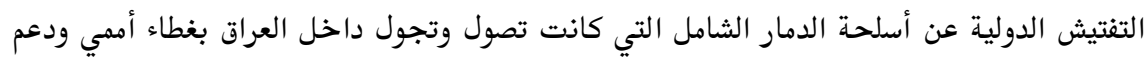

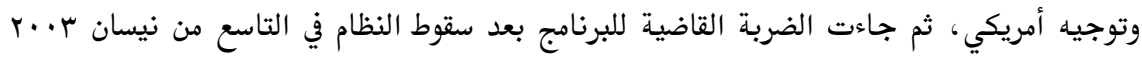

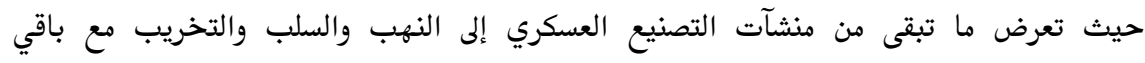
مؤسسات الدولة العراقية، لكن بقى الآلاف من العلماء والباحثين والمهندسين والفنيين العراقيين اللذين انخرطوا في هذا البرنامج موجودين وأغلبهم عاطل عن العمل وهؤلاء يعتبرون في المعايير الاقتصادية موارد ثمينة يجب استثمارها خاصة وان هذه الكوادر كانت ولا تزال علمية حرفية من الأفضل معاملتها خارج التوصيفات والاعتبارات السياسية. أما عن التجربة السعودية في هذا المجال فهي ملفتة للنظر فللمملكة الآن هيئة عامة للتصنيع العسكري تأسست في كانون الثاني 19Ar وتتبع لهذه الهيئة عدد من المجمعات الصناعية مثل فئل

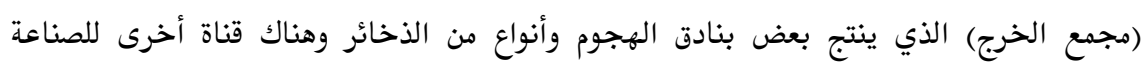

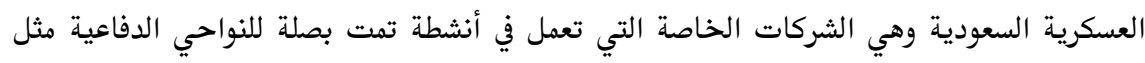

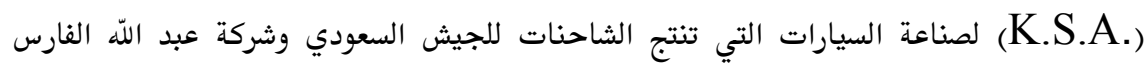

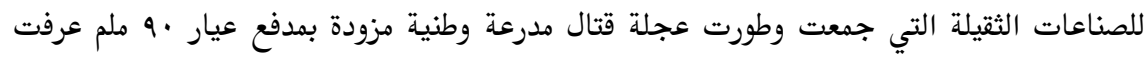

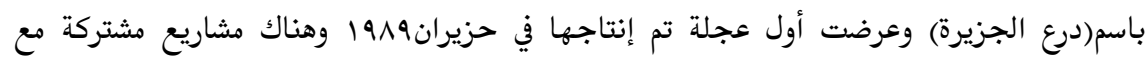
بعض الشركات العالمية الكبيرة مثل مركز تعديل الطائرات ثابتة الجناح والعمودية الذي أنشأته

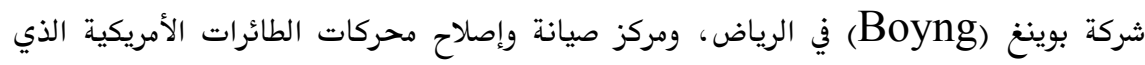

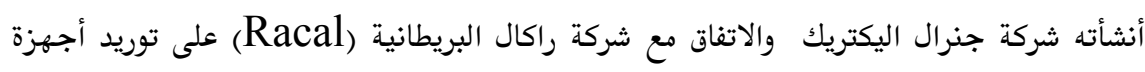
لاسلكية عسكرية ميدانية على شكل أجزاء يتم تجميعها داخل السعودية على ان يزيد الإندان الإسهام المحلي في المنتج النهائي تدريجياً (1). أما دولة الإمارات العربية المتحدة فقد التحقت بنادي التصنيع العسكري وبدأت بإنتاج

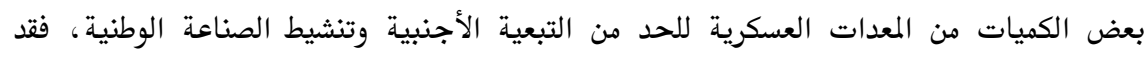
تمكنت شركة أبوظبي لبناء السفن (A.D.S.B.) من أنتاج مجموعة من السفن ذات الاستخدام

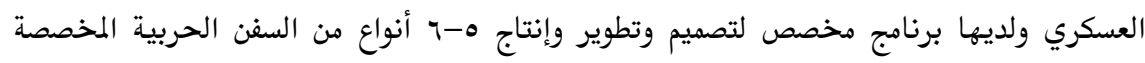


واثق محمد براك

للإبحار في المياه الضحلة في الخليج العربي، كما أنتجت بعض مصانع الإمارات الذخائر وعجلات

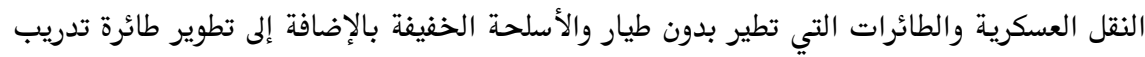
ومقاتلة خفيفة تعتمد على تقنية التخفي تدعى ماكو (Macko) وذلك في تعاون بين القوة الجوية

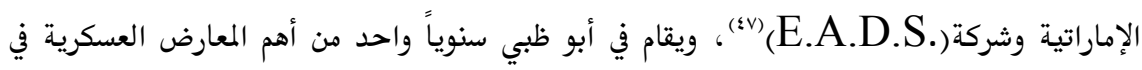
العالم يطلق عليه معرض الدفاع الدولي(أيدكس) حيث تعرض كبريات شركات التصنيع العسكري منتجاتها فيه وتتم خلاله العديد من الصفقات الإستراتيجية المهمة.

r- ألعوامل الخارجية ألمؤثرة على مستقبل العلاقات العسكرية بين العراق ودول الخليج العربية

تبقى العوامل الخارجية شديدة التأثير في قضايا ومتطلبات الأمن القومي لمنطقة الخليج

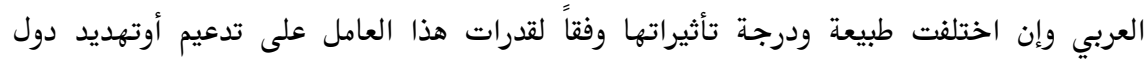
المنطقة، حيث أن القوى الخارجية يمكن أن تشكل احد جانبي المعادلة الدفاعية إذا كانت تمثل تلثئل

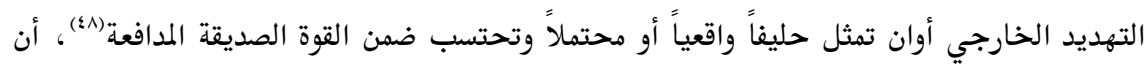
النظام الإقليمية الخليجي يتميز بمكانة مرموقة سواء على مستوى النظام الإقليمية الأكبر أي النظام

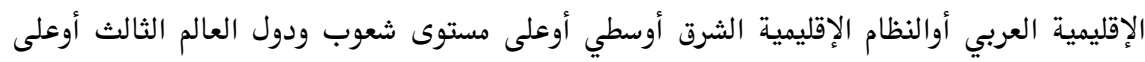

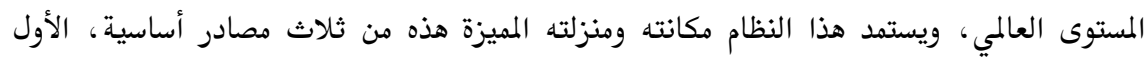
القوة المميزة لإقليم الخليج على مدى التاريخ فقد ظل محط أنظار القوى الدولية الطامحة لتحقيق

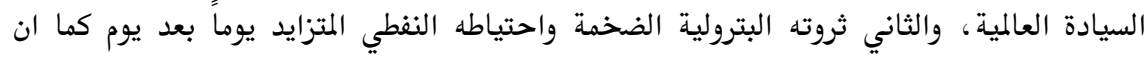
الثروات النقدية التي حصلت عليها دول النظام الإقليمية الخليجي نتيجة عائدات النفط الضخمة اكسب هذه الدول مكانة وأهمية بالنسبة للذظام النقدي العالمي، والمصدر الثالث هوالوزن التاريخي والقيمة الروحية والمعنوية الكبرى لإقليم وشعوب الخليج في التاريخ القديم والمعاصر، فهذا الإقليم الذي كان ههبط الوحي ورسالة الإسلام يضم الحرمين الشريفين في مكة المكرمة والمدينة المنورة

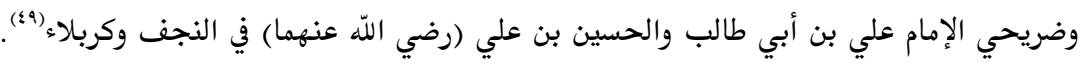
سيتم التركيز في هذا المحور من البحث على العاملين الخارجيين الأمريكي والإيراني

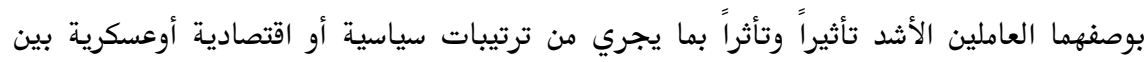


دراسات إقليمية 7 (19)

العراق ودول الخليج العربية، فالزوايا الأربع لمستطيل التوتر في الخليج تضم الفواعل الأربع الرئيسية في النظام الإقليمية الخليجي وهي : إيران ودول مجلس التعاون الخليجي والعراق والولايات المتحدة الأمريكية، وهذه العلاقات المعقدة التي تربط بين هذه الفواعل الأربعة تشمل أشكالا من التعاون والصراع والاستمرارية والتغير (الشكل-1): 


\section{الشكل-1 : مخطط مستطيل التوتر في الخليج}

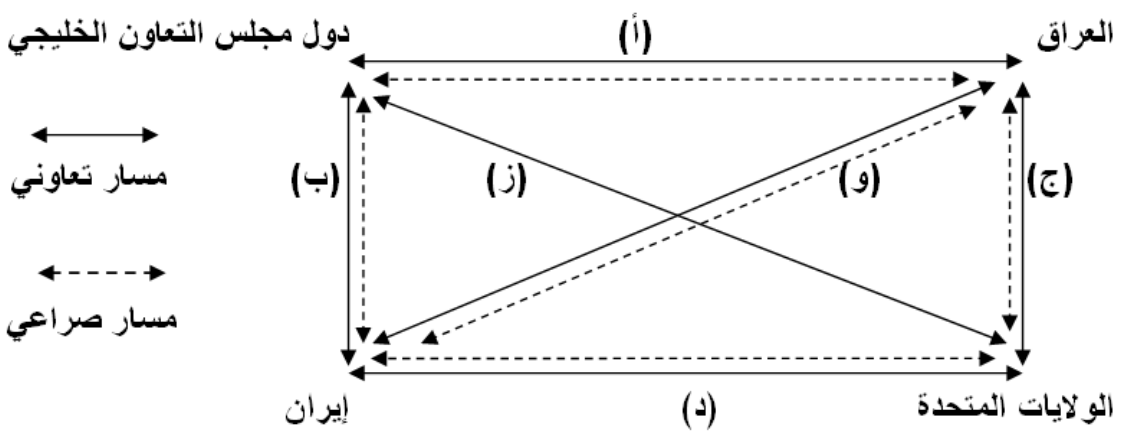

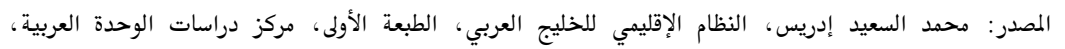

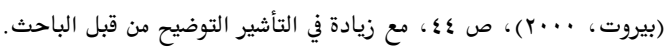

وفق هذا المخطط يمكن توصيف العلاقات في النظام الإقليمية الخليجي كما يأتي:

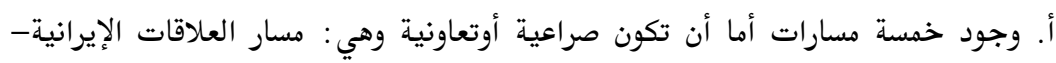

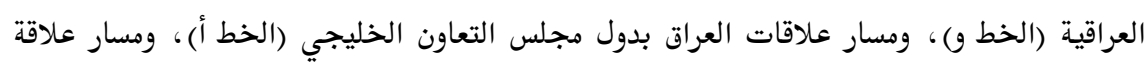

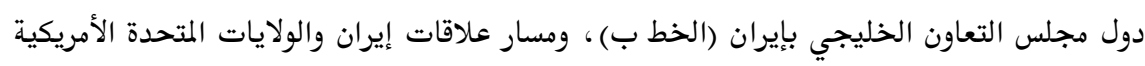

$$
\text { (الخط د)، ومسار علاقات الولايات المتحدة والعراق (الخطج). }
$$

ب. وجود هسار واحد للعلاقات التعاونية المؤكدة ويتركز في العلاقة بين مجلس التعاون

$$
\text { الخليجي والولايات المتحدة الأمريكية (الخطز). }
$$

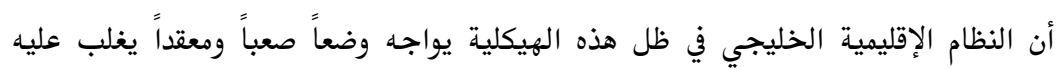

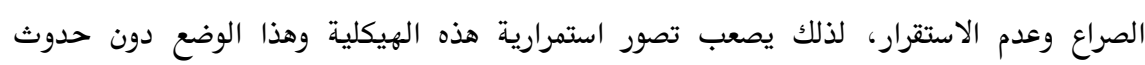
تغييرات جوهرية حقيقية يكون من شأنها نزع أسباب الصراع وإرساء قواعد للتعاون بوصفه السبيل الوحيد للإبقاء على النظام (0.).

في حزيران ب9v1 وصف جوزيف سيسكو (G. Cisco) مساعد وزير الخارجية الأمريكي

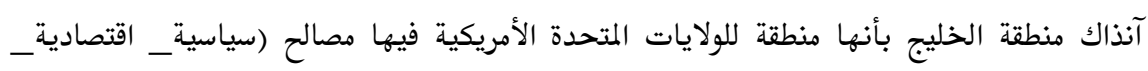

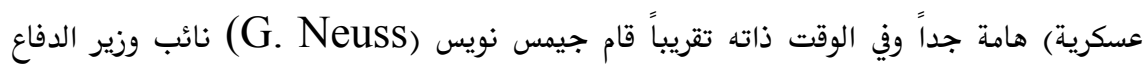

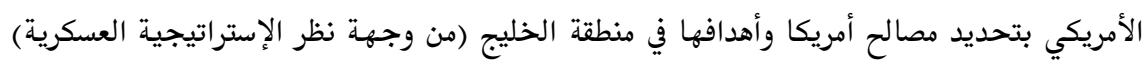


بثلاثة أهداف، ألأول احتواء القوى المناوئة للسياسة الأمريكية، والثاني استمرارية الوصول إلى نفط

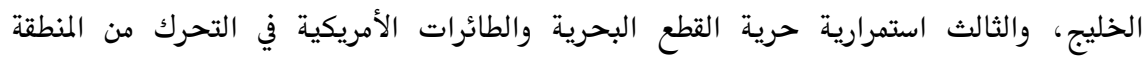

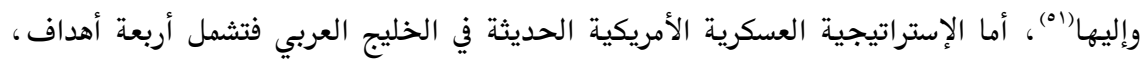

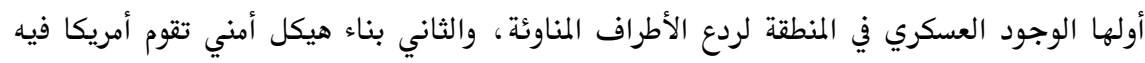
بالدور الرئيس، والثالث أجراء مناورات مع دول المنطقة، والرابع العمل على منع انتشار أسلحة

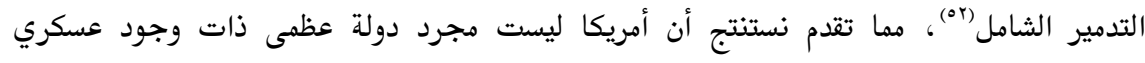

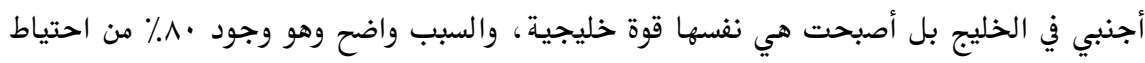

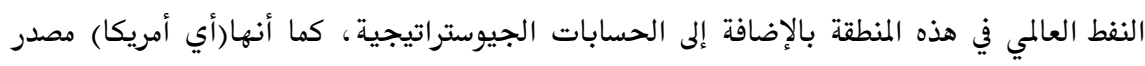

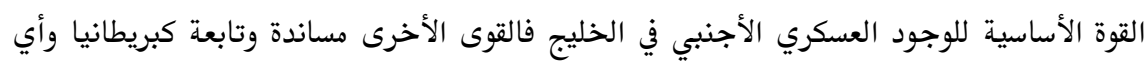

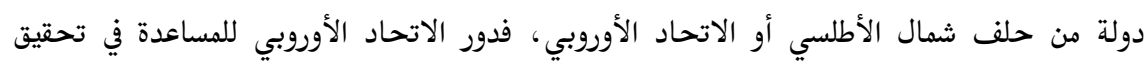

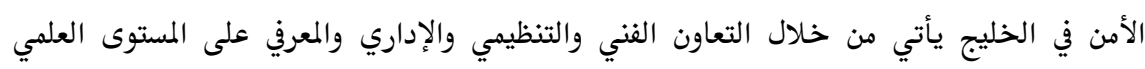

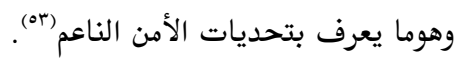

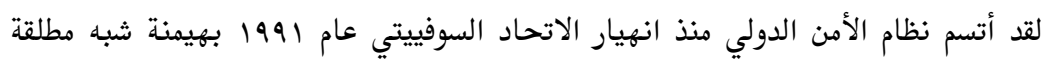

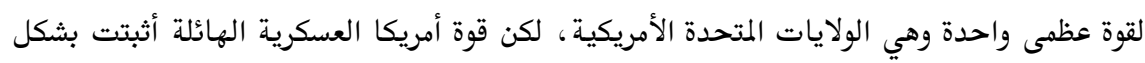

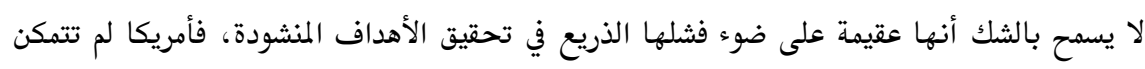

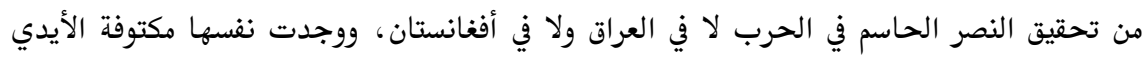

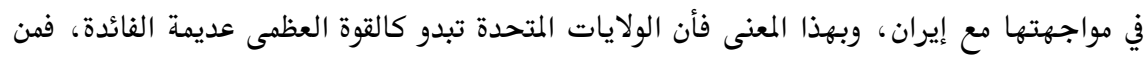

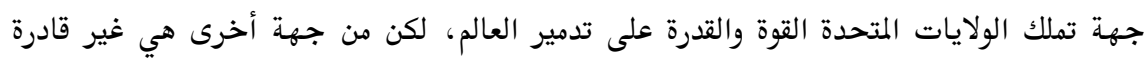

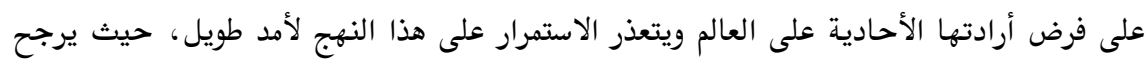

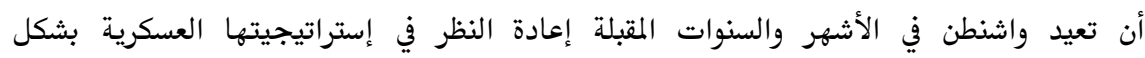
أها عن مرتكزات الترتيبات الإقليمية للأمن في الخليج من وجهة النظر الإيرانية فقد حددت بالتعاون المشترك بين جميع دول الخليج الثمانية (إيران والعراق والسعودية والكويت والإمارات وقطر والبحرين وعمان) علماً أن إيران تعترض على أي اتفاقية أمنية أو دفاعية بين أي دولة من 
دول الخليج وأي دولة غير خليجية سواء كانت عربية أم غير عربية|(00)، إلا أن السلوك الإيراني الحالي في المنطقة ومؤشرات محاولات التدخل في الشؤون الداخلية لبلدان المنطقة يؤجل التفكير

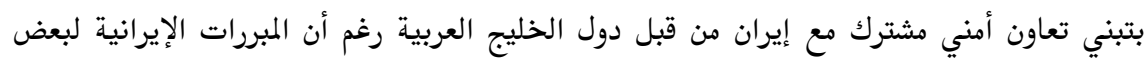

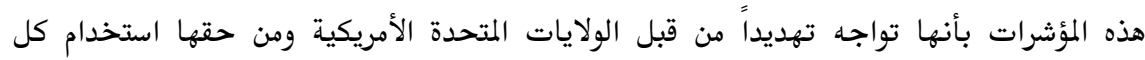
أدواتها في المنطقة لدفاع عن مصالحها وخصوصاً هدفها الإستراتيجي المتمثل بطموحها النووي.

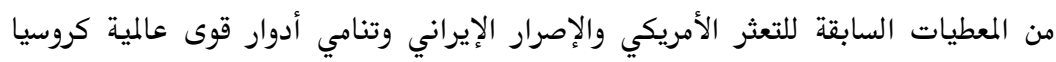

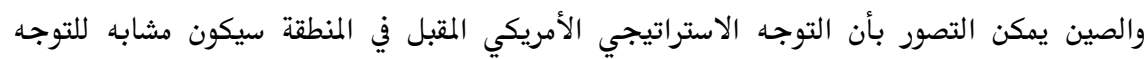

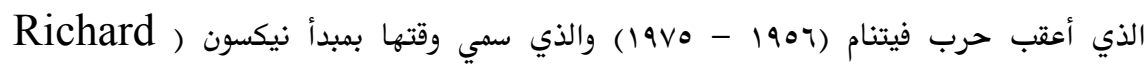
M.Nixon

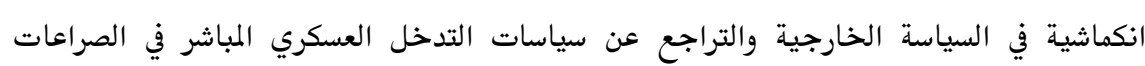
الإقليمية والاستناد على الأسس التالية :أولاً. الامتناع عن التدخل في الشؤون الداخلية للدول الأخرى أو التقليل من حجم التدليه : التدل. ثانياً.تشجيع مشاريع ومحاولات التعاون الإقليمية. ثالثاً.تقديم الدعم اللازم للدول الصديقة في المنطقة لتعزيز مجهوداتها في مجالات الأمن والتنمية(ب9).

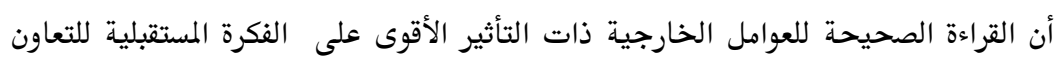

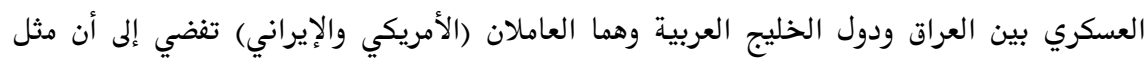

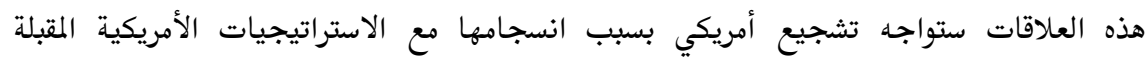

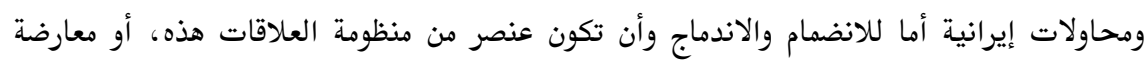
غير جدية أو ليست بمستوى المعارضة التي ستبديها إيران لو كانت هذه العلاقات المزمع إقامتها

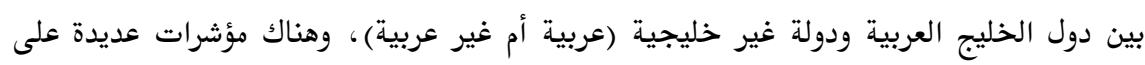
التشجيع الأمريكي لهذه العلاقات، ففي إثناء طرح فكرة الاتفاقية الإستراتيجية بين العراق وأمريكا

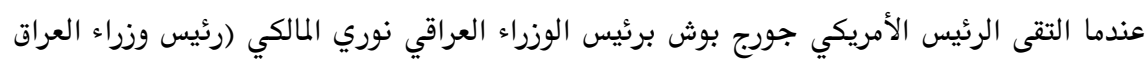

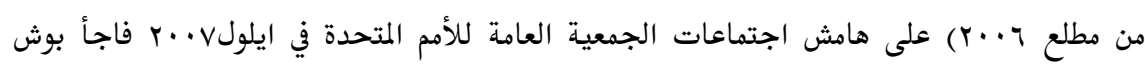

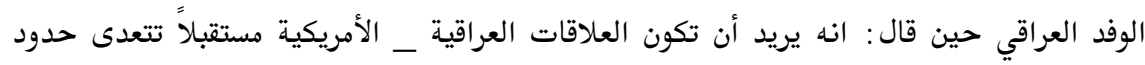
ولايته التي تنتهي مطلع 9...9،كما أضاف انه يريد اتفاقية مع العراق على غرار الاتفاقيات 
الأمريكية مع الدول الخليجية وبالذات المملكة العربية السعودية، مشيراًَأن العراق في حال توقيعه

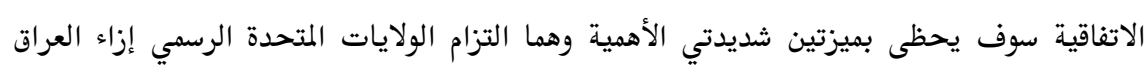

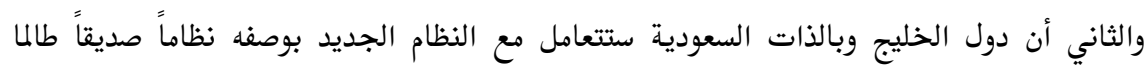

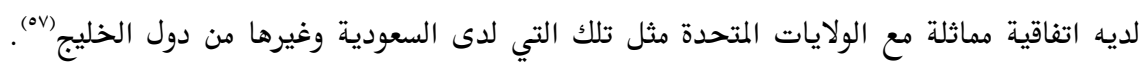

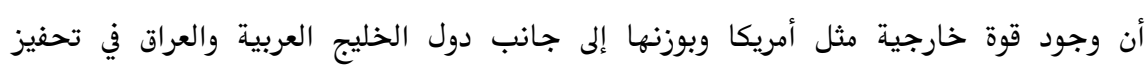
وتشجيع الاندماج مع وجود تهديدات مشتركة لهذه الدول مثل الإرهاب ومحاولات التدخل في

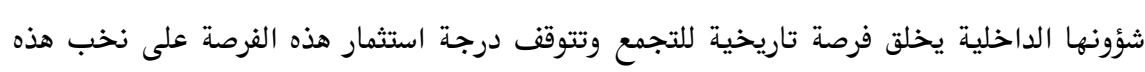

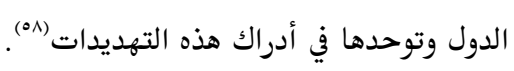
من الضروري الحصول من الولايات المتحدة على التزام واضح بأنها سوف تدعم عملية

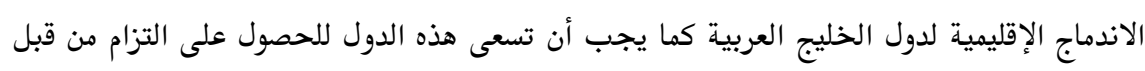

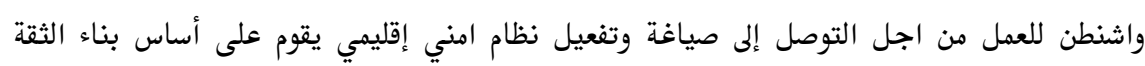

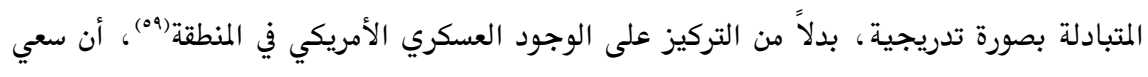

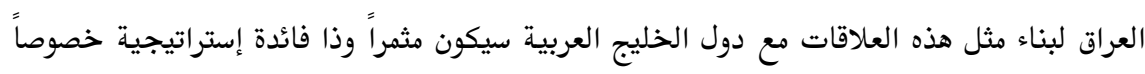

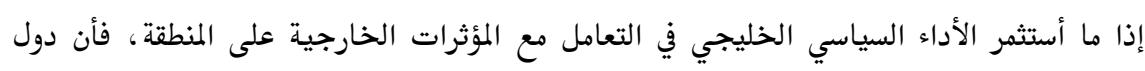

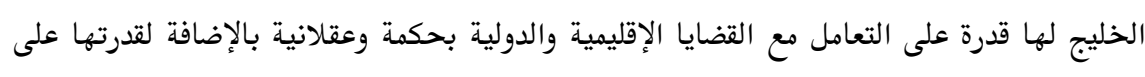

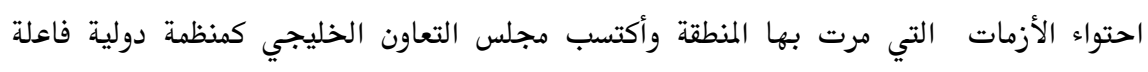

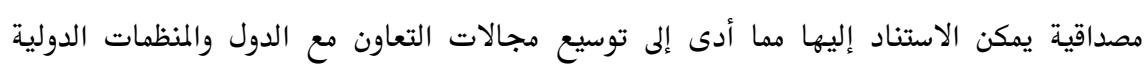

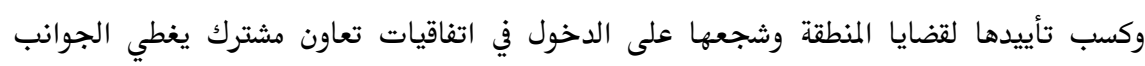
الأمنية والسياسية والاقتصادية(·). أن منطقة الخليج العربي رغم أهميتها الإستراتيجية والثقل السياسي والاقتصادي الذي

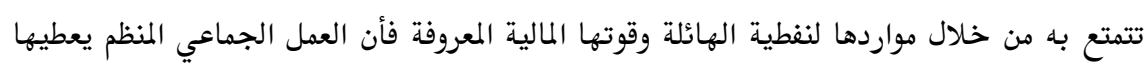

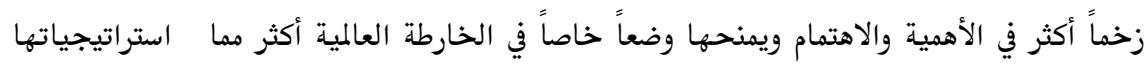

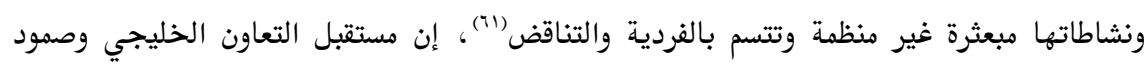


دول المجلس أمام الصراعات والأطماع الدولية المتفاقمة سيكون عاجزاً طالما بقى العراق أكبر الأقطار

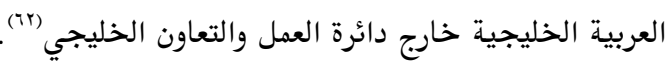

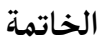

تتغير العلاقات بين الدول بتغير التفاعلات والمصالح المشتركة بينها، وهي تتفاوت حسب الإستراتيجيات والأهداف القريبة المدى لهذه الدول فقد توصف بالتعاون وبمختلف درجاته ومجالاته أو بالنزاع المتمثل بالمواجهات الدبلوماسية في أوطأ درجاته أوقد يصل إلى المواجهة العسكرية، هذا الاستنتاج يفسر طبيعة العلاقات العراقية -الخليجية التي طالما اختلفت توصيفاتها في التاريخ المعاصر، واستناداً للتغيرات التي حدثت في العملية السياسية في العراق وفي علاقاته الخارجية بعد الغزو الأمريكي في آذار ب...r وبالاستناد على الإشارات المشجعة الصادرة من مراكز القرار في دول الخليج العربية يمكن تصور إمكانية الإرتقاء بمستوى العلاقات العراقية-الخليجية لتصل إلى درجة التعاون العسكري، خاصة إذا أخذنا بنظر الاعتبار نجاعة هذا المسلك في ظل

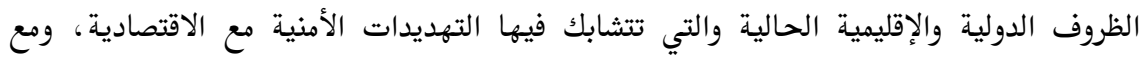

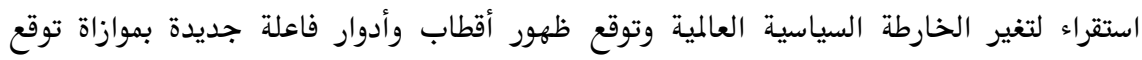
انحسار أدوار كانت ههيمنة للعقود الأخيرة.

بالإمكان تبني نماذج عديدة من التعاون العسكري المستقبلي بين العراق ودول الخليج العربية

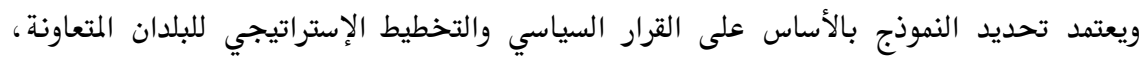

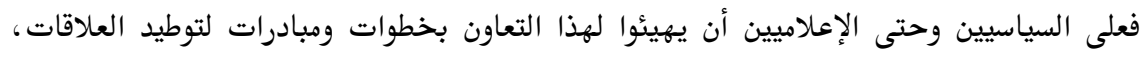
فالتعاون العسكري هو أقصى درجات التعاون السياسي. إذا كان الجيش العراقي الجديد بحاجة إلى مزيد من التدريب الإجمالي على مستوى وحداته وتشكيلاته بالإضافة إلى حاجته للتعرف على المهارات والأساليب التعبوية الحديثة فسيكون

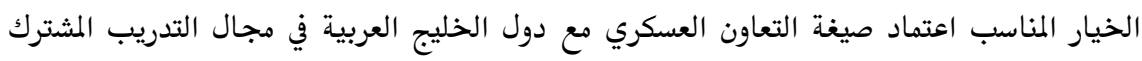
والتمارين التعبوية بالقطعات أو التمارين الهيكلية (تدريب المقرات)، ولمواكبة التطورات والمستجدات في مجال العلوم العسكرية والتعرف على طرق ووسائل التدريب الحديثة والارتقاء بالمستوى العلمي

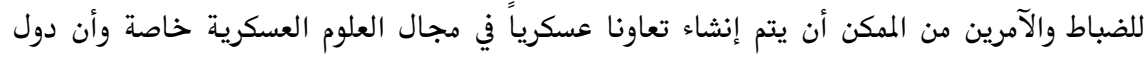


الخليج تحتوي على كليات ومعاهد ومؤسسات تعليمية عسكرية بمستوى ومواصفات عالية لأنها

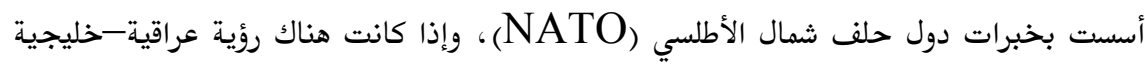

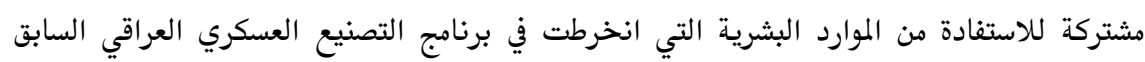

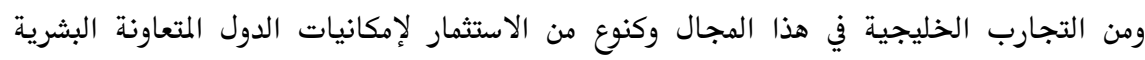

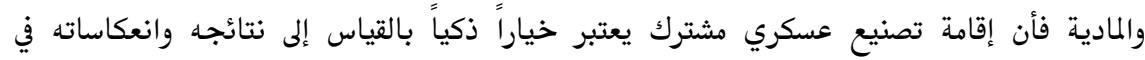

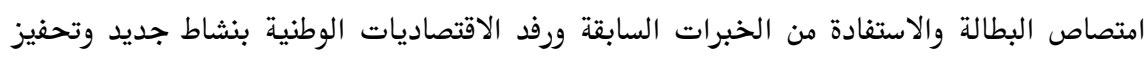
الصناعات الوطنية المرتبطة بالقطاع العسكري كالصلب والكيمياويات. من المؤكد في عالمنا الحالي الذي يصعب التمييز فيه بين المبلدئ المصالح السياسية والأمنية والاقتصادية أن يواجه مشروع التعاون العسكري بين العراق ودول الخليج العربية إذا ما تم تبنيه

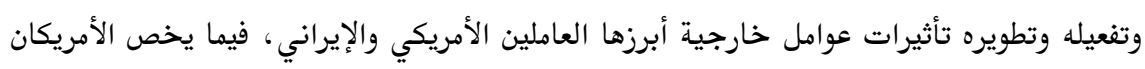

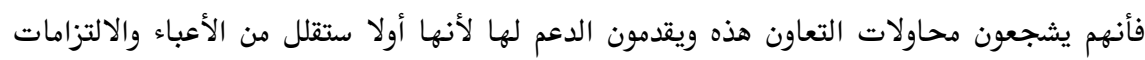

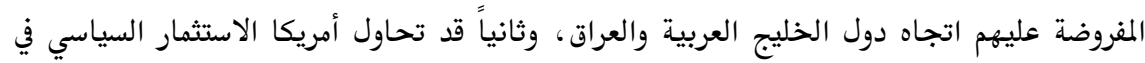

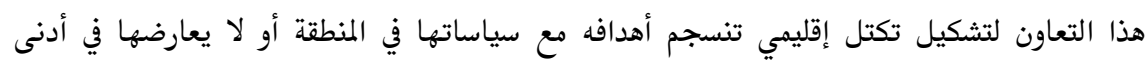

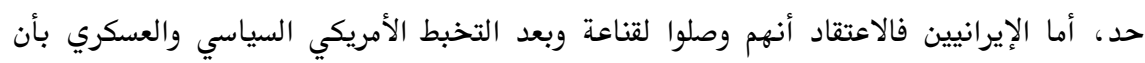

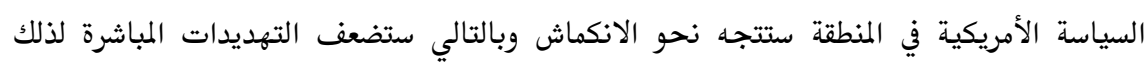
ستكون ردود فعل إيران اتجاه مشروع التعاون هذا أولاً محاولة الانخراط فيه والثاني مراقبته باستمرار وقياس تأثيره على المصالح الإيرانية في المنطقة. 
واثق محمد براك

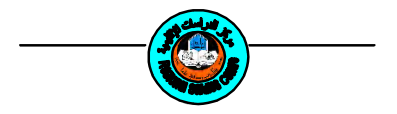

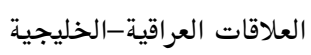

\title{
Iraq-Gulf Prospective Relations In Military Field
}

\author{
Wathig Mohammed Barrack \\ Orsist. Qfecturer, OPlitics Ptrategic Dept.. Regional Pludies \\ Genter, Mbsul Qlniversily.
}

\begin{abstract}
:
The research supposition is based on a prospective vision for a military cooperation between Iraq and Arab Gulf States that involved a briefed description for different stages of Iraqi-Gulf relations in the contemporary history and its changes from inconsistency to attraction or inactivity according to the period condition. Then it focused on these relations after American occupation of Iraq, analyzed gestures and statements by Arab Gulf officials regarding (The New) Iraq, also it defined the possible patterns for military cooperation through reviewing the existing military potency of Arab Gulf states and Iraqi human sources to invest in this field, displaying the Iraqi army deficiency. Moreover the research broached foreign factor affecting that cooperation and concentrated on the American and Iranian elements as the most impacting and being influence.
\end{abstract}




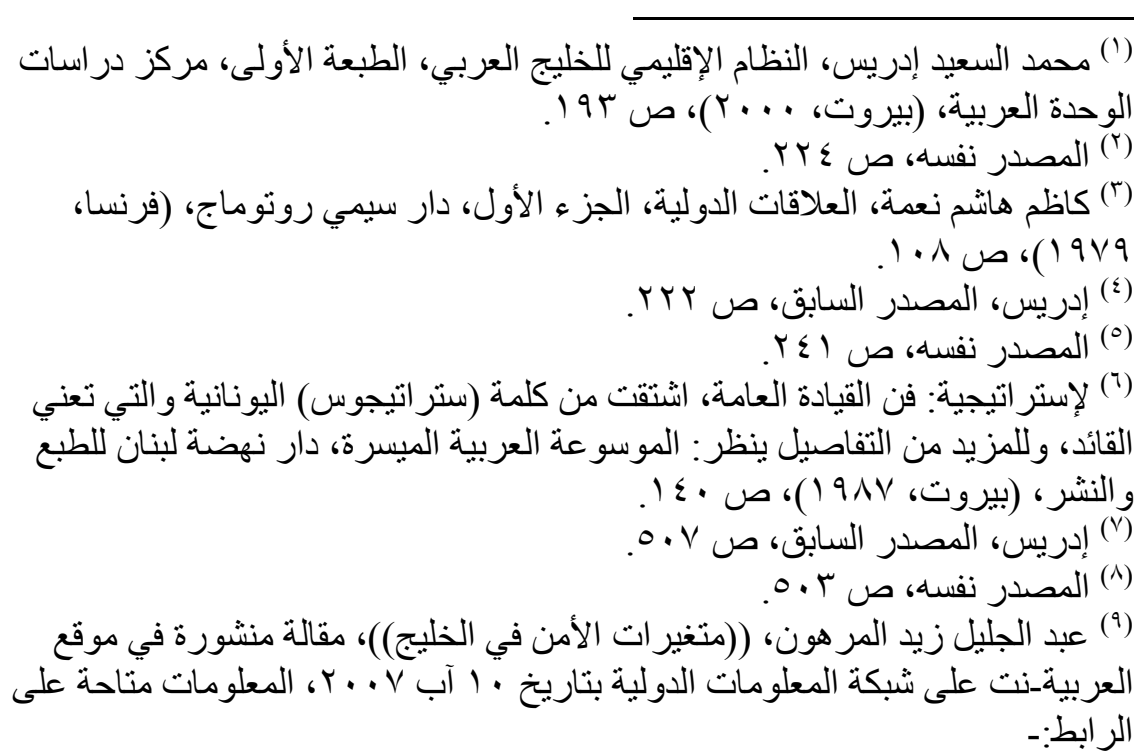

- http://www.alarabiya.net/views/2007/08/10/37684.html

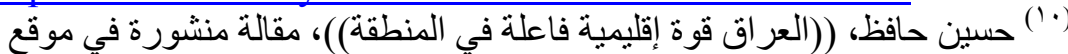

$$
\begin{aligned}
& \text { جريدة الصباح على شبكة المعلومات الدولية، المعلومات متاحة على على الر ابط:- }
\end{aligned}
$$

http://www.alsabaah.com/paper.php?source=akbar\&mlf=interpage $\underline{\& \text { sid }=73442}$

$$
\begin{aligned}
& \text { (' (') صبحي ناظم توفيق، ((علاقات العر اق الإقليمية.. رؤية نحو المستقبل))، مركز }
\end{aligned}
$$

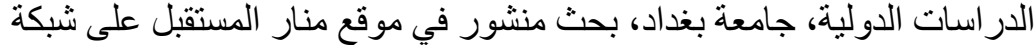

$$
\begin{aligned}
& \text { المعلومات الدولية، المعلومات متاحة على الر ابط: - }
\end{aligned}
$$

- http://mcsr.net/manar/m=2/oo7.html

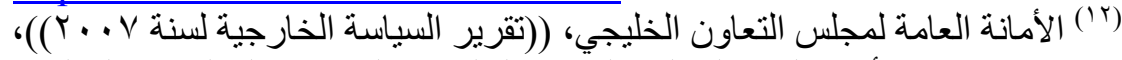

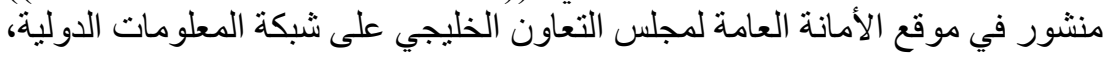
المعلومات متاحة على الر ابط:-

- http://www.gcc-sg.org/index.php?action=Sec-

Show \&ID $=48 \& W 25 \mathrm{ID}=20068$

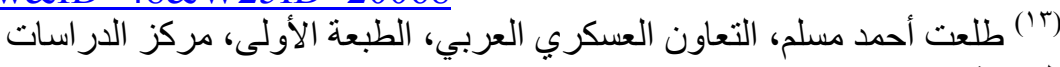

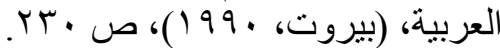




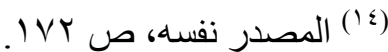

(10) إدوارد ميدإيرل، رواد الإلإستر التيجية الحديثة، ترجمة: محمد عبد الفتاح، الطبعة

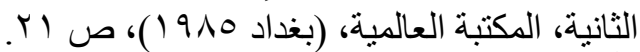

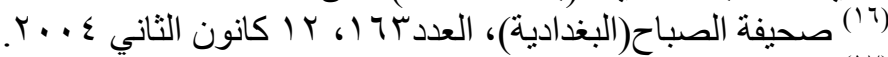
(IV)

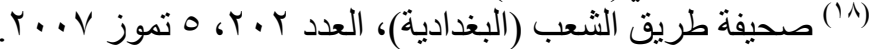

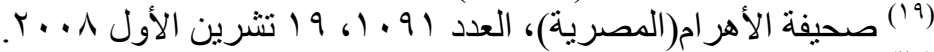

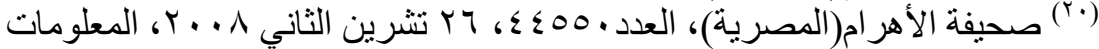
منشورة على موقع الصحيفة في شبكة المعلومات الدولية الدية ومتاحة على الر ابط:- http://www.ahram.org.eg./archive/Index.asp

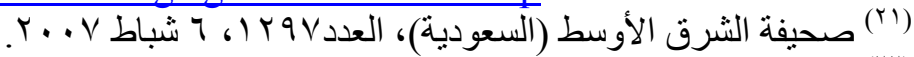

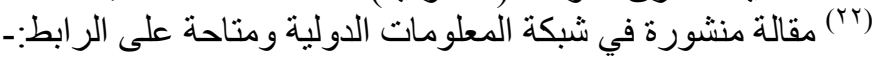
-http://www.daralhayat.com/arab-news/levant-news//06-2008/Item20080605-59f7573d-cDa8-10ed-7e5aad7e4805/story.html (T)

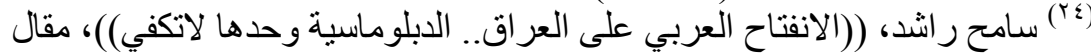

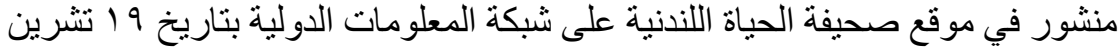

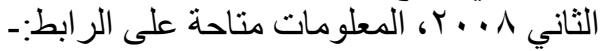
- http:/www.alhayat.com/special/issues/11-2008/Article20081118-bo7e25dl-c0ed-0160-3408b6ab7115/story-html

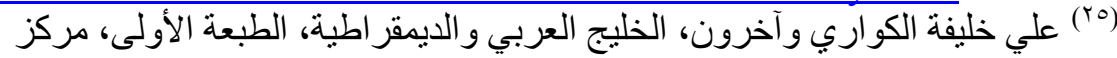

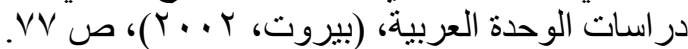

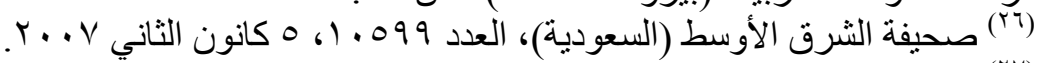

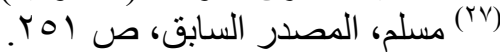

(ب^) حسن مصطفى، التعاون العسكري العربي، الطبعة الثانية، دار الطليعة، (بيروت،

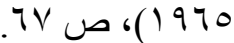

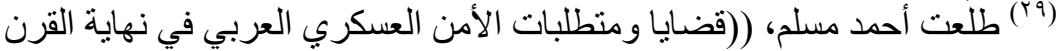

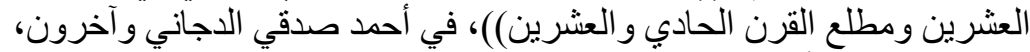

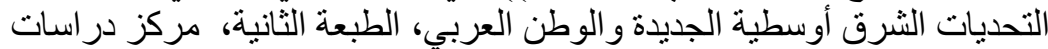

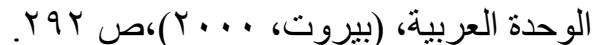

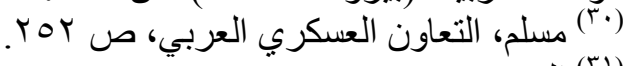

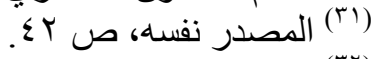

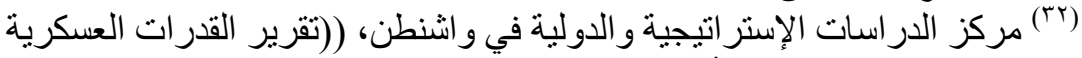

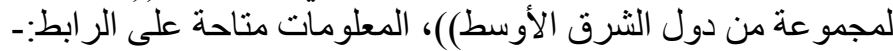
- http://www.taqrir.org/showarticle.cfm?id=428 


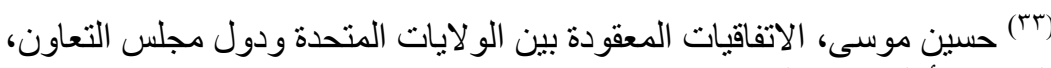

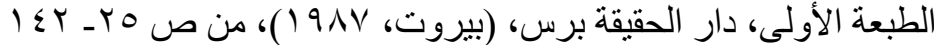

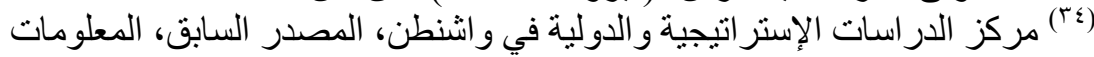

- http://www.taqrir.org/showarticle.cfm?id=468

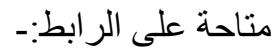

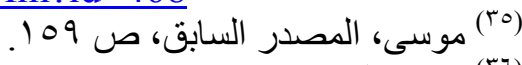

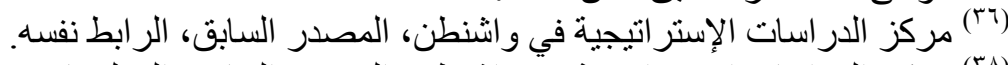

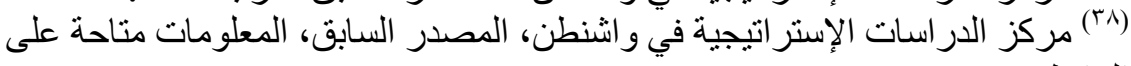

- http://taqrir.0rg/showarticle.cfm?id=428

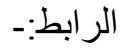
(الرج) مركز الدراسات الإسنر اتيجية في واثنطن، المصدر السابق، المعلومات متاحة على

- http://taqrir.org/showarticle.cfm?id=437 الر ابط:-

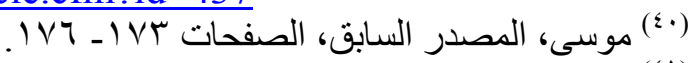

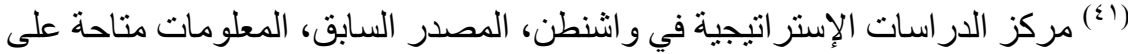

- http://taqrir.org/showarticle.cfm?id=444

$$
\begin{aligned}
& \text { موسى، المصدر السابق، الصفحات (17) } 179 \text { ـ } 179 .
\end{aligned}
$$

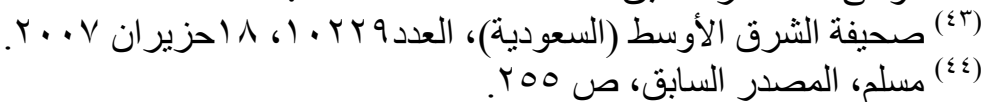

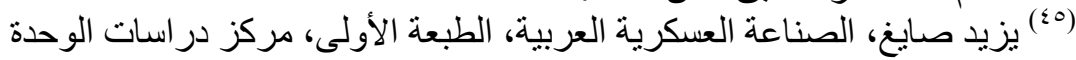

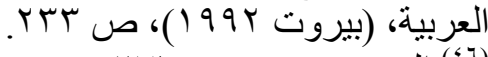

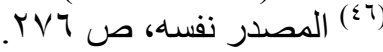

$$
\begin{aligned}
& \text { (\&V) مقالة منشورة في شبكة المعلومات الدولية ومتاحة على الر ابط:- }
\end{aligned}
$$

- http://bo7maid44.multiply.com/journal/item/5

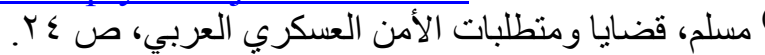

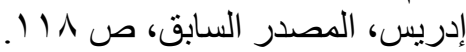

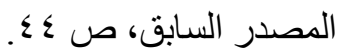

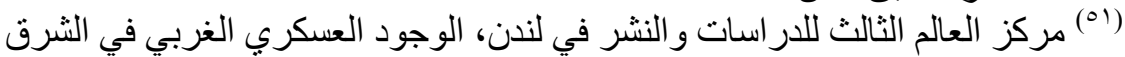

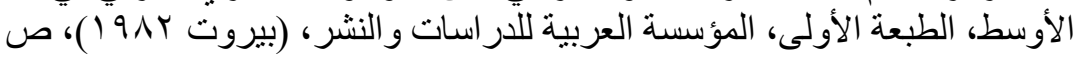


واثق محمد براك

- http://faculty.ksu.edu.su/20722/DocLib/

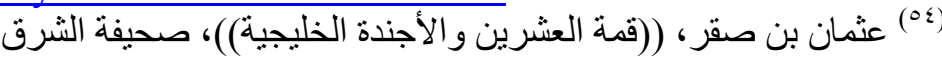

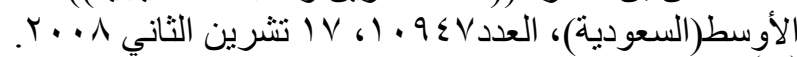

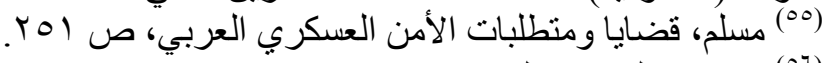

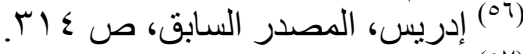

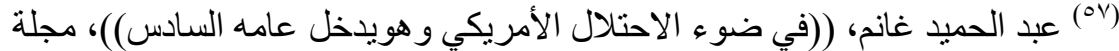

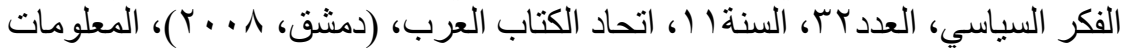

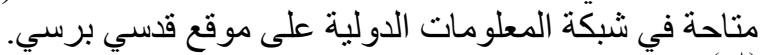

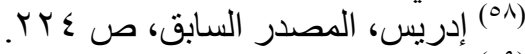

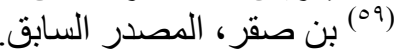
("7) الأمانة العامة لمجلس التعاون الخليجي، المصدر السابق.

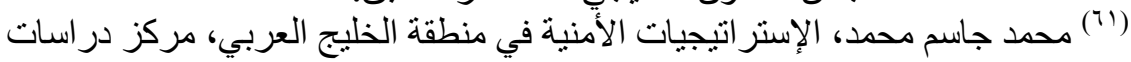

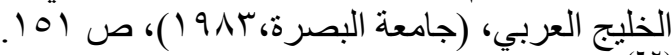

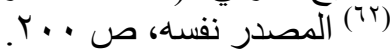

